\title{
Perceiving SARS-CoV2 Mpro and PLpro dual inhibitors from pool of recognized antiviral compounds of endophytic microbes: an in-silico simulation study
}

Jignesh Prajapati

Gujarat University

Rohit Patel

Gujarat University

Priyashi Rao

Gujarat University

Meenu Saraf

Gujarat University

Rakesh Rawal

Gujarat University

Dweipayan Goswami ( $\nabla$ dweipayan.goswami@gujaratuniversity.ac.in )

Gujarat University

\section{Research Article}

Keywords: SARS-CoV-2, Antiviral, Papain-like protease (PLpro), Main protease (Mpro), endophytes, Molecular dynamics simulation

Posted Date: August 23rd, 2021

DOI: https://doi.org/10.21203/rs.3.rs-829046/v1

License: (c) (i) This work is licensed under a Creative Commons Attribution 4.0 International License. Read Full License 
1 Perceiving SARS-CoV2 Mpro and PLpro dual inhibitors from pool of recognized 2 antiviral compounds of endophytic microbes: an in-silico simulation study

3 Jignesh Prajapati ${ }^{11}$, Rohit Patel ${ }^{2 \#}$, Priyashi Rao', Meenu Saraf ${ }^{2}$, Rakesh Rawal ${ }^{1}$,

4 Dweipayan Goswami ${ }^{2 *}$

5 'Department of Biochemistry \& Forensic Science, University School of Sciences, Gujarat

6 University, Ahmedabad 380009, Gujarat, India.

$7 \quad{ }^{2}$ Department of Microbiology \& Biotechnology, University School of Sciences, Gujarat

8 University, Ahmedabad 380009, Gujarat, India.

9

Jignesh Prajapati (ORCID: 0000-0001-8700-9929)

Rohit Patel (ORCID: 0000-0002-7077-4218)

Priyashi Rao (ORCID: 0000-0002-7203-8249)

Meenu Saraf (ORCID: 0000-0003-4964-9452)

Rakesh Rawal (ORCID: 0000-0002-7985-1187)

Dweipayan Goswami (ORCID: 0000-0003-0165-0294)

\# Jignesh Prajapati and Rohit Patel have contributed equally and are equal first authors.

*Details of correspondence

Dr. Dweipayan Goswami

Assistant Professor,

Department of Microbiology \& Biotechnology,

University School of Sciences, Gujarat University,

Ahmedabad 380009, Gujarat, India

Email: dweipayan.goswami@gujaratuniversity.ac.in

Authors Approval

All authors have seen and approved the manuscript. 


\section{Abstract}

The enormous impact of SARS-CoV2 continues and scientific community is seeking to discover the tactics to impede the spread of virus. The essential result is attenuated, and genetically engineered vaccines are being driven into the market with the general effectiveness being around $80 \%$. Therefore, vaccination is not the sole answer for combat this pandemic. The substitute methodology is adapted to target on this virus with a medication in blend with existing vaccines. Papain like protease (nsp-3; nonstructural protein) and Mpro (nsp-5; nonstructural protein) of novel corona virus are the ideal target to develop drugs as they play different roles that are essential for viral development and replication. Utilizing computational methodology, we plan to distinguish a plausible microbial metabolite as analogue of GRL0617 (the well-established inhibitor of PLpro) and X77 (the well-established inhibitor of Mpro) from the pool of known antiviral compounds of endophytic microbes to interact and inhibit PLpro and Mpro as dual inhibitors. In the wake of collecting known antiviral compounds of endophytic microbes and screened them through pharmacophore hypothesis, molecular docking, and dynamics simulation, we perceive Cytonic acid A and Cytonic acid B to be seen as the potent PLpro and Mpro dual inhibitors using rigorous computational methods.

Keywords: SARS-CoV-2; Antiviral; Papain-like protease (PLpro); Main protease (Mpro); 
Coronavirus disease 19 (COVID-19) is a new SARS-CoV2 linked disease that manifests as a range of clinical signs going from asymptomatic, minor influenza like manifestations to acute respiratory distress, pneumonia, and demise ${ }^{1,2}$. COVID-19 pandemic shown up over eighteen months prior and flipped around our lives. During the first wave of the infection, all affected countries endorsed various precautionary measures, including a total or partial lockdown of residents, instructed social distancing, wearing of face masks, and frequent hand sanitization. More significantly, individuals did not follow the prevention measures precisely and the number of affected individuals changed relying upon how powerful the prevention measures were; however, it never went to naught. Additionally, these recommended measures have been headed to the detriment of the economy and more crucially, these severe control measures alone are not viable enough to stop the COVID-19 pandemic. This is vividly observed in both developing and developed countries, where people were hit by a third wave of corona virus infection due to a lack of antiviral medication or vaccination, and as a result, the scientists from around the world are prompted to find effective medications and vaccines for COVID-19 treatment and prevention ${ }^{1,3}$.

In last one year, COVID-19 vaccines are being developed using various strategies, rendered from typical inactivated and live attenuated vaccines to more innovative messenger RNA (mRNA) and DNA technologies, like viral vector and subunit vaccines ${ }^{4-6}$. For instance, BBV152 is a classical inactivated whole virion vaccine while, mRNA-1273 and mRNABNT162b2 are mRNA-based vaccines that target SARS-CoV2 spike protein ${ }^{5}$. Herd immunity may hypothetically be achieved because of the high incidence of protection from infection after vaccination. Besides, there are yet various vaccination related inquiries that presently unaddressed, include the length of a vaccination preventive effects and cross-protection against viral variants (Alpha, Beta, Gamma, Delta, Delta Plus, Epsilon, Eta, Theta, lota, Kappa, and Lambda), particularly new mutations ${ }^{7}$. New cases of COVID-19 are dropping as vaccination rates rise, but the list of variants is probably going to grow as new mutation develops, which is the reason using vaccines to tackle the pandemic still has a long way to go 8 .

Until vaccine-induced herd immunity is established, another promising strategy would be to foster new drugs that are compelling against SARS-CoV2. Virus replication necessitates a certain set of structural and non-structural proteins. Absence of these proteins can limit hostto-host transfer or replication, culminating in virus spread suppression. As a result, medicines that can regulate the accessibility of these proteins should be pursued. SARS-CoV2 has a 30-kb RNA genome that encodes two large overlapping polyprotein precursors (pp1a and 
pp1ab), which are acted on by viral proteases like Main protease (Mpro) and Papain-like protease (PLpro) to generate 16 non-structural proteins (NSPs) involved in viral replication, transcription, and assembly of the virus nuclear material into the capsid protein coat (Figure 1). Consequently, inhibiting these proteases may have a considerable impact on the viral machinery and the overall rate of viral infection. Scientist around the globe have well considered these proteases (Mpro and PLpro) as important drug targets for developing medications as inhibiting these proteases directly halts the functioning and replication of SARS-CoV2, making the virus feeble.

Bioactive and natural products derived from plants, microorganisms, and animals have long been recommended to treat infectious and non-infectious disorders, and they keep on assuming a significant part for drug development in the wake of this twenty-first-century pandemic ${ }^{9}$. The likelihood of discovering novel medications using metagenomic databases of natural compounds has increased as computer hardware and software technologies has progressed. Several investigations have used advanced computational tools such as docking, molecular dynamics simulation, and a combination of advanced silico approaches to find natural compounds from large database that could be used as possible lead compounds ${ }^{10-13}$. However, this is like looking for a needle in a haystack while trying to discover the suitable molecule from a large database. The use of a specific library of small compound could aid in the exploration of the suitable molecule. Antiviral metabolites from endophytic origin are still not investigated against the SARS-CoV2 proteases (Mpro and PLpro), consequently they can be used as a source for specified small compound library.

Endophytes are microorganisms that live within plant tissues with mutualistic association for at least part of their life cycle without causing any apparent disease manifestation ${ }^{14}$. Research on endophytic fungi have evinced that, they are an auspicious resource of bioactive compounds and to access this valuable source, the diversity of endophytic fungi and their species richness in different parts of world has been explored. Large number of secondary metabolites, especially from fungal endophytes are extracted, isolated, and characterized, such as Emodin, $\omega$-hydroxyemodin, (+)-Sclerotiorin, Phomopsone B and Phomopsone $\mathrm{C}$, which possess viral protease inhibition activity ${ }^{15-18}$.

In present study, we have manually curated previously recognized antiviral compounds obtained from endophytic microorganisms and prepared a library to endeavoured to virtually screen them as a dual inhibitor for Mpro and PLpro with therapeutic potential to act simultaneously on the activity of both proteases. Cytonic acid A and Cytonic acid B were selected as dual protease inhibitor after pharmacophore screening, molecular docking, ADMET (Absorption-Distribution-Metabolism-Excretion-Toxicity) profile and binding energy 
calculation through MM-GBSA assay. Moreover, to analyze the nature of ligand-protein interaction, a 100ns molecular dynamic (MD) simulation was undertaken for Cytonic acid derivatives and control compounds under simulated physiological conditions. We anticipate that Cytonic acid A and Cytonic acid B as dual-target therapeutic approach for COVID-19 could be more effective and would substantially reduce the use of combinational drugs as well as the multi-drug dose load in the host system.

\section{Materials and methods}

\section{Protein preparation}

PLpro protein of SARS-CoV2 (PDB ID: 7CMD) co-crystalized form with GRL0617 and Mpro of SARS-CoV2 (PDB ID: 6W63) co-crystalized form with $X 77$ were retrieved from protein databank (PDB) ${ }^{19-21}$. Here, GRL0617 and X77 are the known inhibitors for respective proteins and were used as reference. Proteins were imported to Schrödinger Maestro and were prepared in Protein preparation wizard (PrepWizard) of Maestro. In which, each of the protein was first pre-processed by adding hydrogens, converting selenomethionines to methionines and het states were generated Epik for $\mathrm{pH}$ 7.0. In the next step of protein preparation, $\mathrm{H}$-bond assignment was done using PROPKA for $\mathrm{pH} 7.0$ for optimizing the protein. Once the protein was optimized, the restrained minimization of protein was done using OPLS2005 (Optimized Kanhesia for Liquid Simulations) force field.

\section{Meta data curation for Ligand Library development}

Electronic databases such as PubMed, Science Direct, Scopus and Google Scholar were used for data collection of endophytic microorganisms and its bioactive metabolites. Based on experimental antiviral effects of metabolites against various viruses such as influenza, H1N1, HIV, HCV, and EV-71, the 45 antiviral compounds were retrieved from published studies. Table 1 lists the 45 compounds present in the library, along with their isolation sources and bioactivity. All the ligands were retrieved in SDF format and were imported to the Schrödinger Maestro for ligand preparation for docking. LigPrep wizard in Schrödinger Maestro was used to generate ionization states for each ligand structure with Epik at a physiological $\mathrm{pH}$ of $7.2 \pm 0.2$ unit. Rest other options were kept as default and the ligands were minimized under OPLS2005 force field. The output files prepared on ligand minimization was used for docking using Glide.

\section{Generation of E-pharmacophore model}

An energy-optimized pharmacophore (E-pharmacophore) hypothesis was generated separately using the crystal structure of (i) SARS-CoV-2 PLpro bound to an inhibitor GRL0617 with a resolution of $2.1 \AA$ (PDB ID: 7CMD) and (ii) SARS-CoV-2 Mpro bound to an inhibitor 
X77 with a resolution of $2.1 \AA$ (PDB ID: 6W63). During pre-processing of the complex, water molecules within $5 \AA$ distance of the ligand were eliminated from the structure and then minimized complex was used to develop E-pharmacophore model 34,35. 'Develop Pharmacophore from Protein-Ligand Complex' option in the Phase module was used to create the E-pharmacophore model. The minimized complex was then imported into the workspace, where default pharmacophore properties like hydrogen bond acceptor $(A)$, hydrogen bond donor $(D)$, aromatic ring $(R)$, and hydrophobicity $(H)$ were mapped. The functional groups in the bioactivity of the targeted enzyme (PLpro) are included in the generated pharmacophore hypothesis. On performing E-Pharmacophore, two hypotheses were generated one for each protein-ligand complex. These E-Pharmacophore hypothesis were then used for screening of ligands.

\section{E-pharmacophore based virtual screening}

A pharmacophore-based virtual screening for prepared library of 45 compounds was carried out using the Phase module of the Schrodinger suite to develop a collection of compounds with the requisite molecular characteristics for optimal binding to PLpro and Mpro, as mapped by the selected E-pharmacophore models.

\section{Molecular Docking}

The optimized and minimized proteins from the previous step were used for docking. The first step for docking is to prepare the grid at the exact same co-ordinates as that of native ligand GRL0617 in 7CMD for PLpro and X77 in 6W63 for Mpro. The grid for PLpro was developed at the co-ordinates, $X-34.22, Y-11.61, Z-30.05$, with the size $10 \AA$ X $11 \AA$ X $14 \AA$ while for Mpro, grid was developed at the co-ordinates, $X-20.58, Y$ 18.1, Z -26.98, with the size $12 \AA$ X $14 \AA$ X $15 \AA$, using 'Receptor grid generation' feature of Glide module in Schrödinger Maestro. For docking, the output file of (i) receptor grid generation and (ii) minimized ligands obtained after E-pharmacophore based screening (15 for PLpro and 18 for Mpro) were imported in the 'Ligand docking' window of Glide module in Schrödinger Maestro. Moreover, native ligand GRL0617 for PLpro and X77 for Mpro were used as positive controls for docking with respective proteins, PLpro and Mpro. Under the settings, the precision of docking was set as 'Extra Precision (XP)', Ligand sampling was set as 'Flexible' and the Epik state penalties were added to docking score. After docking, single pose with minimum binding energy $(\mathrm{kcal} / \mathrm{mol})$ was selected for further studies. Selected pose for each ligand was opened in BIOVIA Discovery Studio (DS) visualizer for analysis of interactions taking place beteween ligand and amino acids of protein. Ligands capable of producing maximum interactions with target protein like GRL0617 (for PLpro) and X77 (for Mpro), were selected for MM-GBSA assessment. 


\section{MM-GBSA calculation}

Molecular mechanics generalized Born surface area (MM-GBSA) calculation was used to calculate the binding free energy change ${ }^{36-39}$. Docked ligand-receptor complexes were minimized using local optimization feature present in Prime wizard of Maestro (Schrödinger Release 2017-4). Binding energy for each receptor-ligand complex was determined by using OPLS-2005 force field. Equation employed for free energy calculation is as follows:

$\Delta \mathrm{GBind}=\Delta \mathrm{EMM}+\Delta \mathrm{GSolv}+\Delta \mathrm{GSA}$

Here, $\triangle \mathrm{EMM}$ represents the variation between the minimized energy of the receptorligand complexes; $\triangle G$ Solv represents the variation between the GBSA solvation energy of the receptor-ligand complexes and the sum of the solvation energies for the protein and ligand. In $\triangle G S A$ contains some of the surface area energies in the protein and ligand and the difference in the surface area energies for the complexes. The minimization of the docked complexes was done using a local optimization feature of prime.

\section{ADMET analysis}

The ADMET properties of the GRL0617, X77 (as controls) and top screened ligands (test endophytic molecules) were predicted using the pkCSM - pharmacokinetics server ${ }^{40}$ that predicted both physiochemical and pharmacological properties. To perform this analysis SMILES (Simplified Molecule Input Line Entry Specification) of the compounds were retrieved from PubChem and uploaded to pkCSM - pharmacokinetics server. Parameters computed by server include Water solubility in buffer system (SK atomic types, mg/L), in-vivo CaCO2 cell permeability (Human colorectal carcinoma), Human intestinal absorption (HIA, \%), in-vivo Pglycoprotein inhibition and in-vivo skin permeability (logKp, cm/hour). Metabolic parameters were determined using in-vivo Cytochrome P450 2C19 inhibition, in-vivo Cytochrome P450 2C9 inhibition, in-vivo Cytochrome P450 2D6 inhibition, in-vivo Cytochrome P450 2D6 substrate, in-vivo Cytochrome P450 3A4 inhibition and in-vivo Cytochrome P450 3A4 substrate. Distribution property included tests like, Blood-Brain Barrier (BBB) penetration, Lipinski's Rule (Rule of Five), Central Nervous System (CNS) permeability. To access the toxicity of compounds under study a range of important endpoints including, Acute algae toxicity, Ames test, two years carcinogenicity bioassay in mouse, two years carcinogenicity bioassay in rat, in-vivo Ames test result in TA100 strain (Metabolic activation by rat liver homogenate) were computed. Excretion again is an especially important parameter and as many drugs often withdrawn at clinical trial stages due to their poorer renal clearance. In this study we included Total Renal clearance and Renal OCT2 Substrate to identify Excretion efficacy of the proposed metabolite. 


\section{Validation Through MD Simulation}

Desmond (Schrödinger Release 2018-4) by D.E. Shaw research was used to perform simulation of SARS-CoV2 PLpro Mpro in the presence of various ligands. As Cytonic acid A and Cytonic acid B were having good binding energy, proper ADMET profile and able to mimic interactions of native ligand with PLpro as well as Mpro, MD simulation was carried out for following complexes: (I) PLpro-GRL0617, (II) PLpro-Cytonic acid A, (III) PLpro-Cytonic acid B, (IV) Mpro-X77, (V) Mpro-Cytonic acid A and (VI) Mpro-Cytonic acid B. To ensure the accuracy of results of MD simulation, PLpro-GRL0617 and Mpro-X77 complexes were used as control set and results produced by Cytonic acid $A$ and Cytonic acid $B$ with both the proteins were compared with it. For preparation of complexes and apply pre-simulation protein relaxation, Protein Preparation Wizard was used. Parameters for simulation were kept as following: solvent model: TIP3P; box shape: orthorhombic; with the buffer space around the periphery of protein as $10 \AA$. Once these parameters were defined $\mathrm{Cl}^{-}$or $\mathrm{Na}^{+}$counter ions were added to perform neutralization. Steepest descent energy minimization was performed, and the simulation was proceeded for 100 ns with NPT (constant Number of particles, Pressure, and Temperature) with $300 \mathrm{~K}$ and 1.01 bar, constant volume, Smooth Particle Mesh Ewald (PME) method. After simulation, simulation interaction diagram wizard was used to evaluate the trajectories for root mean square deviation (RMSD), root means square fluctuation (RMSF), Ligand-protein contact profiles, and for Ligand \& Protein modifications.

\section{Results}

\section{Meta data assessment for ligand library development}

The prepared library for this in silico analysis included a specialised library composed of 45 compounds of endophyte origin with in vitro anti-viral activity against various viruses such as influenza, H1N1, HIV, HCV, and EV-71. Table 1 contains the library, which includes the names of the compounds, their endophyte sources, and antiviral efficacy against particular viruses.

\section{Structure-based pharmacophore modelling}

Receptor-pharmacophore based on the 3D structure of a target protein can provide detailed and accurate information on ligand interaction attributes. $\mathrm{H}$-bond donors, acceptors, positive and negative ionizable groups, lipophilic regions, and aromatic rings are the most commonly used descriptors in pharmacophore modelling. The most successful 3D structurebased e-pharmacophores were made utilizing the receptor-ligand pharmacophore generation procedure employed in PHASE, which was used to discover potentially essential amino acids implicated in ligand binding for a co-crystal GRL0617 inhibitor within the binding site of PLpro 
(Figure 2a) and for a co-crystal X77 inhibitor within the binding site of Mpro (Figure 2c). $\mathrm{H}$ -

260 bond acceptor, $\mathrm{H}$-bond donor, and pi-pi stacking of aromatic ring was among the five key 3D attributes of the generated e-pharmacophore for the evaluated protein. Figure $2 \mathrm{~b}$ depicts the five 3D pharmacophore characteristics for PLpro-GRL0617 complex, which include two donor hydrogen bonds, one acceptor hydrogen bond, and one aromatic ring sphere while, Figure $2 \mathrm{~d}$ depicts the five 3D pharmacophore characteristics for Mpro-X77 complex, which include two acceptor hydrogen bond, and three aromatic ring spheres.

\section{Pharmacophore-based virtual screening analysis}

The 45 potential anti-viral compounds of endophytes origin (Table 1) were screened using the e-pharmacophore hypothesis created from the GRL0617-PLpro complex and X77Mpro. The PHASE screen score and corresponding binding sites variables were used to filter these substances. Execution of proposed pharmacophore hypothesis, a total of 15 molecules managed to pass this filter for PLpro-GRL0167 complex (Table 2) and 18 molecules for MproX77 complex (Table 3).

\section{Molecular Docking analysis}

For the first set of docking, the minimized 3D molecular structure of co-crystallized inhibitor GRL0617 was docked into the active site of viral PLpro after successive defining of the grid box utilizing Glide's Receptor Grid Generation tool in Maestro. Investigation of the cocrystallized inhibitor (GRL0617) revealed its molecular interaction with the binding site of viral protease SARS-CoV2-PLpro. Generally, the hydrophobic interactions drive the binding of GRL0617 with PLpro of SARS-CoV2 that confers inhibition of protein. The 1-naphthyl moiety of the aromatic rings frames the major contact as a pi-pi interaction with Tyr264 and Tyr268, is somewhat less presented to solvent and fits in to the cavity at the locus that oblige the leucine at the P4 position. Besides, the 1-naphthyl moiety interacts with the side chains of Pro247 and Pro248. The (R)-methyl group at GRL0167's stereocenter places itself inside the protein in the narrow area between Tyr264 and Thr301, where it fits in the limited polar space. Apart from the 1-naphthyl moiety, GRL0617 also has a single aromatic ring with - NH2 at R3 position, which is positioned at the cavity's opening. The cavity is polar owing to the presence of numerous polar groups, such as the side chain oxygens of Gln269 and the hydroxyl group of Tyr268, which essentially participate in the interaction by filling in as hydrogen bond acceptor. Total 15 microbial metabolites obtained after pharmacophore screening were considered for molecular docking investigation using Glide XP lead optimization protocol of Schrodinger suit. Four fungal metabolites of endophytic origin, Aspergilline E, Cytonic acid A, Cytonic acid $B$ and 4-dehydroxyaltersolanol A produced significant binding energies along with multiple conserved interactions with Tyr268 of SARS-CoV2-PLpro. Each of these molecules 
produced the binding energies of $-7.7,-7.655,-7.292$ and $-6.859 \mathrm{kcal} / \mathrm{mol}$, respectively (Table 4). The interactions between these antiviral compounds and the protein (PLpro) are depicted in Figure 3, and the structural features of GRL0617 and the top four antiviral metabolites are listed in Table 5.

Similarly, for the second set of docking, the minimized 3D molecular structure of cocrystallized inhibitor X77 was docked into the active site of viral Mpro after successive defining of the grid box utilizing Glide's Receptor Grid Generation tool in Maestro. Investigation of the co-crystallized inhibitor (X77) revealed its molecular interaction with the binding site of viral protease SARS-CoV2-Mpro. Several hydrogen bonding, pi-stacking, and hydrophobic interactions appear to be involved in the co-crystallized binding site. Non-Covalent inhibitor X77 interacts with Asn142, Gly143, Glu166 and His41 with hydrogen bond. Additionally, ligand clubbed between the benzene ring of Phe140 and the imidazole ring of His172 and forms pipi interaction with Cys145 and His41. Furthermore, it forms hydrophobic interaction with different amino acid present in binding site, Thr25, Leu27, Ser144, Phe140, Leu141, His172, Leu167, Tyr54, His164, Gln189, Met165 and Pro168.

The top four molecules from endophytes that showed to effectively bind with Mpro are Cytonic acid B, Cytonic acid A, Asperphenalenone D and Asperphenalenone A, respectively with the binding energy of $-9.998,-9.798,-8.969$ and -6.2417 (Table 4). The compound with the best docking score, Cytonic acid $B$ makes six hydrogen bonds with the amino acids namely, Thr24, Thr26, Asn142, Glu166, Arg188 and Thr190; along with it forms pi-anion interaction with Cys145. Moreover, hydrophobic interaction in the form of alkyl/pi-alkyl interaction with His41, Met49, Met165 are being formed. Apart from these, Van der Walls interactions with this ligand is formed by 13 different amino acids as represented in the Figure 4. Cytonic acid A tends to form hydrogen bonds with Thr24, Asn142, Glu166, and Arg188, while alkyl/pi-alkyl interaction forms with Cys44, Thr26, Met49 and Met165 while forming several Van der Walls interactions with amino acids in the active site. The third best compound, based on the docking score, Asperphenalenone $\mathrm{D}$ makes hydrogen bonds with five amino acids, namely Thr25, Gly143, Cys145, Glu166, and Thr190. It forms hydrophobic interaction by making Alkyl/pi-alkyl interaction with His41, Met49, Met165, and Pro168 along with making Van der Walls interactions with several amino acids in the active site of Mpro. Lastly, Asperphenalenone D makes hydrogen bonds with His41, Asn119, Gly143, and Glu166; makes hydrophobic interactions in the form of alkyl/pi-alkyl interactions with Met49, Tyr118, Leu141, Cys145 and Met165. Like other ligands, this also makes Van der Walls interactions with several other amino acids in the active site of Mpro. The interactions between these antiviral compounds and the protein (Mpro) are depicted in Figure 4. Moreover, the 
ligand properties of the reference inhibitors and top screened ligands of endophytic origins for both, PLpro and Mpro are represented in Table 5.

\section{MM-GBSA analysis}

Receptor-ligand interaction causes modulation of energies of both free receptor and ligand ( $\Delta \mathrm{GBind}$ ) furthermore, these energies also have significant impact on stability of receptor-ligand complex. In general, negative energies represents the higher stability of any system. Various energies produced during MM-GBSA for 7CMD with native ligand GRL0617 as well as top four docking hits are presented in Table 4. Here, binding energies of GRL0617 with both $7 \mathrm{CMD}(-67.56 \mathrm{Kcal} / \mathrm{mol})$ is in negative which suggests the higher spontaneity of interaction. Similarly, among tested compounds Cytonic acid A ranks highest in terms of stability with $-58.96 \mathrm{Kcal} / \mathrm{mol}$ binding energy, whereas Cytonic acid $B$ is the second highest ranking compound with $-50.9 \mathrm{Kcal} / \mathrm{mol}$ binding energy. MM-GBSA energies of the rest of the tested compounds were also in negative but the values were relatively higher which suggest low occurrence rate for the complex. Compound Aspergilline E produced the highest docking score with SARS-CoV2-PLpro but the $\Delta$ GBind energy $(-50.81 \mathrm{Kcal} / \mathrm{mol})$ was found to be the higher than Cytonic acid derivatives.

Similarly, for Mpro, based on the $\Delta G B i n d$ scores of reference compound and ligands, reference ligand $X 77$ shows the best $\Delta G$ Bind score of $-79.89 \mathrm{Kcal} / \mathrm{mol}$, while of all the other test ligands of endophytic origins, Cytonic acid $A$ has the best $\Delta G B$ ind score of -75.30 $\mathrm{Kcal} / \mathrm{mol}$, followed by the Cytonic acid B, Asperphenalenone $\mathrm{D}$, and Asperphenalenone $A$ where they show the $\Delta$ GBind scores of $-67.68 \mathrm{Kcal} / \mathrm{mol}, 65.91 \mathrm{Kcal} / \mathrm{mol}$ and $50.46 \mathrm{Kcal} / \mathrm{mol}$ respectively. Apart from $\Delta G B i n d$ energy, calculations for energy, Hydrogen-bonding correction, Lipophilic energy, pi-pi packing correction and Van der Waals energy is also provided in Table 6.

\section{ADMET analysis}

All the ADMET properties of the test compounds along with reference compounds GRL0617 and X77 are presented in Table 7. For any drugs to work on human body five properties play very crucial role that are absorption, distribution, metabolism, excretion, and toxicity. Property of absorption was measured using seven different models. Here, to assess the effectiveness of selected compound as oral drug $\mathrm{CaCO} 2$ permeability, and intestinal absorption were measured. Analysis revealed that all the compounds except Cytonic acid $A$ and Cytonic acid $\mathrm{B}$ has higher values for $\mathrm{CaCO} 2$ permeability. However, Cytonic acid $A$ and Cytonic acid B have 47 and $62.6 \%$ human intestinal absorption, respectively. Moreover, assessment of skin permeability was lowest for all the tested as well as control compounds which suggest minimum absorption. To evaluate the transport of the compounds across the 
membrane three tests for P-glycoprotein were performed where test compounds were tested as a substrate of the P-glycoprotein and inhibitors of the P-glycoprotein I and II. All the compounds were found to be the compatible substrates which suggests that they can pass across the membrane using ATP-binding cassette (ABC) transporter. Whereas assay as an inhibitor of P-glycoprotein I and II were found to be negative for all compounds except Aspergilline $\mathrm{E}$, which highlights the inability of this compound to inhibit both these efflux pumps of foreign substances. To measure the distribution of the compounds throughout the body four assays were used namely they are volume of distribution (VDss), fraction unbound, blood brain barrier (BBB) permeability, and central nervous system (CNS) permeability. VDss assay is used to measure the total quantity of drugs needed for uniform distribution of drugs throughout the blood. Values for the assay for all the compounds were found to be lower than $0.45 \log \mathrm{L} / \mathrm{kg}$, which suggests that lower drug volume will be required. For Cytonic acid $B$, this value was found to be the least $-1.707 \log \mathrm{L} / \mathrm{kg}$. BBB permeability of the Cytonic acid $A$ and Cytonic acid $B$ were found to be -1.896 and -1.782 , respectively which suggests lower permeability, whereas this value for reference inhibitor GRL0617 and X77 were obtained in positive intiger values. Values for CNS permeability were also negative for all compounds under study; hence compounds are predicted to have lower permeability for CNS. Metabolism of the test drugs within body was evaluated using seven different models of cytochrome where test compounds were evaluated for their ability to act as a substrate for CYP2D6 and CYP3A4 further these compounds were assayed for the inhibition of CYP1A2, CYP2C19, CYP2C9, CYP2D6, and CYP3A4. Cytonic acid A, Cytonic acid B and all the other test compounds were found to be negative for all the seven different models of cytochrome, except for Asperphenalenone $D$ and Asperphenalenone A predicted to interact with CYP3A4. Excretion of the compounds from the body was assessed using two models that are total clearance and renal OCT2 assay. All the test compounds and GRL0167 were found to be negative for the renal OCT2 assay hence none of them can be excreted using organic cation transporter 2 with $X 77$ to be an only exception. Whereas total clearance assessment produces the value of $0.268 \mathrm{~mL} / \mathrm{min} / \mathrm{kg}$ for Cytonic acid A which is higher than GRL0617. Toxicity assessment was carried out with 10 different models. All the four test molecules were found to be negative for the AMES test which suggests that these compounds are not carcinogenic or mutagenic, whereas GRL0617 was reported positive for this test. For the Cytonic acid A and Cytonic acid $B$, maximum recommended tolerated dose values were found to be highest that is 0.44 and $0.467 \mathrm{log}(\mathrm{mg} / \mathrm{kg} /$ day), respectively. Among the drugs hERG (human ether-a-go-go gene) I and II inhibitors are not favored as inhibition of this genes have been reported to cause QT syndrome which can lead to the fatal ventricular arrhythmia. Here, all the test compounds including control (GRL0617 and X77) were found to be negative as the inhibitor of hERG I whereas for hERG II, GRL0617 was found to be positive as an inhibitor. Oral rat acute and 
chronic toxicity values for Cytonic acid A and Cytonic acid B were higher than that of GRL0617 which suggests that relatively higher doses of the compound are producing toxicity. Detailed values of the ADMET analysis are given in the Table 7.

\section{Molecular dynamic simulations}

Among the docked compounds two isomeric compounds Cytonic acid A and B, previously reported as inhibitors of human cytomegalovirus protease (hCMV), were found to be producing docking scores and MM-GBSA energies within ideal ranges for both PLpro and Mpro. Hence, both compounds were further processed using MD simulation assay to determine the protein-ligand complex stability for $100 \mathrm{~ns}$. Here, along with test compound (Cytonic acid A and B), simulation of GRL0617 with SARS-CoV2-PLpro and X77 with SARSCoV2-Mpro were also performed as a control set for respective protein.

Once MD simulation was performed, the Root Mean Square Deviation (RMSD) values for all the frames present in trajectory were calculated. In general, RMSD value of any simulation represents the modulations that take place in the state of specific atoms with reference to their initial state. Here, to generate the RMSD value docked pose of protein-ligand complex was considered as an initial state or reference pose. Y-axis (left) of Figure 5 and Figure 6 represents the RMSD value of protein atoms. Analysis of this plot for PLpro-GRL0617 (Figure 5) reveals that protein backbone attains the equilibration at RMSD value of $2.3 \pm 0.5$ $\AA$, while Mpro-X77 (Figure 6) reveals that protein backbone attains the equilibration at RMSD value of $2.2 \pm 0.6 \AA$. Here, the RMSD value after equilibration is not exceeding $4 \AA$ for all the complexes under study at the peak end which is good. For the smaller and most globular proteins RMSD value is ideally supposed to be in the range of 1.0-4.0 $\AA$. For proteins that are bigger in size this value might exceed the upper boundary limit of $4.0 \AA$. For the complex of PLpro-Cytonic acid A (Figure 5), RMSD value remains within the accepted limits considering the size of protein. Here, RMSD value is centered in the range of $2.0 \pm 0.5 \AA$ and during the entire simulation RMSD value of protein remains within this range. Whereas for PLpro-Cytonic acid $B, R M S D$ value is equilibrated at $2.3 \pm 0.5 \AA$. Similarly for complexes, Mpro-Cytonic acid A, and Mpro-Cytonic acid B (Figure 6) the protein backbone RMSD never exceeds $3.5 \AA$. In the graphs of Figure 5 right $Y$-axis represents the ligand RMSD value which provides the insight on the stability of the docked ligand pose in the binding pocket. 'Lig Fit Prot' signifies the RMSD values of ligand with reference to protein backbone. This value is ideally supposed to be in the vicinity of protein backbone RMSD value (difference of 3-4 $\AA$ ) but slightly higher than that of protein RMSD value are also acceptable. Presence of significantly higher value suggests the major changes in ligand pose compared to that of docked pose. Throughout the whole simulation 'Lig Fit Prot' value of PLpro-GRL0617 (Figure 5) complex is in the range of 
$1.5 \pm 0.5 \AA$. Whereas, for the -PLpro-Cytonic acid A complex this value is found to be $5.5 \pm 1 \AA$ although it is higher than that of protein RMSD, value is still within the acceptable range. For, PLpro-Cytonic acid B this value is $4.5 \pm 1 \AA$ which slightly lower than that of Cytonic acid A which suggest the relatively higher stability of the complex. On the other hand, 'Lig Fit Lig' value of GRL0617 is lower than that of both Cytonic acid isomers which suggests changes in the binding pose of ligand, but the difference is not that bigger. Such results shows that GRL0617 is having relatively higher stability compared to the tested ligand in binding pocket at the given docking pose. Similarly, for Mpro-GRL0617 the 'Lig Fit Prot' values peak up to the maximum of $4.0 \AA$ at few instances through course of simulation, while for Mpro-Cytonic acid A and Mpro-Cytonic acid B the RMSD values peaks at $6.5 \AA$ and $7.3 \AA$, for Mpro-Cytonic acid A the small spike in the value from 2.5 to $6.5 \AA$ at $\sim 40 \mathrm{~ns}$ suggests the ligand reorienting and then stabilizing suggested by the RMSD value falling back to $\sim 4.0 \AA$ at around $55 \mathrm{~ns}$ (Figure 6). For all the ligands, the 'Lig Fit Prot' values attain nice plateau suggesting the interaction between protein and ligand being stable.

For the extensive study of the interactions produced during the course of simulation Figure 7 to 10 were used. Figure 7 represents the interactions made by reference ligand (GRL0617) and test compounds (Cytonic acid A and Cytonic acid B) with PLpro where the interaction types with percent interaction during 100 ns MD simulation run is represented. Similarly, for Mpro the interactions made by reference ligand (X77) and test compounds (Cytonic acid A and Cytonic acid B) is represented in Figure 8.

Figure 9 represents the interaction fraction of reference ligand (GRL0617) and test compounds (Cytonic acid A and Cytonic acid B) with PLpro while Figure 10 represents the interaction fraction of reference ligand $(X 77)$ and test compounds (Cytonic acid $A$ and Cytonic acid B) with Mpro. Hydrogen bonds, hydrophobic interactions such as Pi cation, Pi-Pi stacking, water bridges and ionic interactions made by ligand with amino acids of proteins during 100 ns MD simulation is represented in these figures. Among these variety of interactions ionic interactions were found to be absent in both control and test ligand. For all the graphs in Figure 9 and 10, the stacked bar charts are normalized over the course of the trajectory, for example, a value of 0.7 suggests that $70 \%$ of the simulation time the specific interaction is maintained. Values over 1.0 are possible as some protein residue may make multiple contacts of same subtype with the ligand. All the bar charts in Figure 9 and 10 suggests all the ligands (reference inhibitor and test compounds) forms strong interactions with several amino acids of PLpro and Mpro respectively. At several instances the interaction fraction shoots above 0.8 , which shows 
Protein-ligand interaction timeline ligands interacting with PLpro and Mpro are represented in Figure 11 and 12 respectively. These diagrams show the instances of a ligand interacting with a particular amino acid with respect to time and with what intensity. For instance, in Figure 11, GRL0617 interacts with Pro248, Tyr264, Try268 and GIn269 strongly and evenly through the 100 ns of simulation. Similarly, Cytonic acid A and Cytonic acid B also interacts with various amino acids such as Glu161, Leu162, Asp164, Pro248, Tyr264, Tyr268, GIn269 and Tyr273 effectively. Similarly in Figure 12, X77 effectively interacts with His41, Asn142, Gly143, His163 and Glu166 of Mpro. Here like PLpro, Cytonic acid A and Cytonic acid $B$ interacts with various amino acids of Mpro during the MD simulation. Thus, from the evidence of Docking, MM-GBSA, and MD simulations it can be deduced that Cytonic acid A and Cytonic acid B might serve as dual inhibitor of PLpro and Mpro.

\section{Discussion}

Covid consists of group of viruses known to infect humans and other animals. Biological features of this group of viruses mostly remains the same such as genomic material consists of positive strand of RNA and S-, E-, M- and N-protein are the most common protein found in all the members of the group. These viruses belong to subfamily coronaviriae which is further separated into four different genus that are namely, (I) Alpha Coronavirus, (ii) Beta Coronavirus, (iii) Gamma Coronavirus, (vii) Delta Coronavirus. Here, Alpha and beta coronavirus are frequently observed in humans and animals whereas gamma and delta primarily target the birds. For instance, MERS-CoV and SARS-CoV both are the Beta Coronavirus that respectively causes Middle East Respiratory Syndrome, or MERS and Serious Intense Respiratory Disorder, or SARS. Our most recent opponent SARS-CoV-2, causative agent of COVID-19, is also the member of beta coronaviruses. Apart from these viruses, Porcine Transmissible Gastroenteritis Virus (TGEV), Bovine Coronavirus (BCV), Avian Infectious Bronchitis Virus (IBV), Feline Infectious Peritonitis Virus (FIPV), Canine Coronavirus (CCoV), Porcine Hemagglutinating Encephalomyelitis Virus (HEV), and Turkey Coronavirus are also members of coronavirinae subfamily ${ }^{1}$, but they are unable to infect humans as they lack the necessary S-proteins for cellular entry. MERS, and SARS- CoV have S-protein that can interact with ACE2 receptor and facilitate the viral entry in human cells ${ }^{41-}$ 43. S-proteins are specific for hosts hence cross infection is uncommon but on occasions it has been noted for instance SARS-CoV (2003) was transferred to humans from bats. Similarly, MERS-CoV (2005) was primarily infecting camels but cross infections in humans were also noted. Recently, member of Covid group, SARS-CoV2, is noted as infectious agents in humans due to cross infectivity. Moreover, such instances are more frequently occurring 
Apart from vaccine development, scientific communities have also devoted their energies and resources to identify compounds that can counter the SARS-CoV2 virus ${ }^{10,46,47}$.

507 For identification of such compounds, docking and MD simulations have been frequently utilized ${ }^{2,48-50}$. Variety of natural products from bacteria, fungi, and plants have been explored to inhibit the crucial viral proteins as their natural origin makes them vastly available. For instance, Pyranonigrin A, Flaviolin and Sterenin M are fungal metabolites and their docking and simulation studies with Mpro suggests that they can inhibit the viral replication via interacting with this protein 11,13,51. Flavonoids, Dorsilurin E and Euchrenone a11 were proposed as allosteric inhibitors of Mpro ${ }^{52}$. Furthermore, many other studies were carried out in silico using molecular dynamic simulation and docking studies ${ }^{53-55}$. In addition, these approaches have also been utilized for potency assessment of hydroxychloroquine against various potential targets of SARS-CoV2 ${ }^{56}$. In all of these studies the rationale is very basic that if any of these molecule can meddle with the viral proteins then they can hinder the normal life cycle of the virus ${ }^{57,58}$.

Endophytic microbes are symbiotically associated with plants and have been proven to produce novel or analogues of host bioactive metabolites exhibiting a variety of biological activities including antiviral activity ${ }^{59}$. However, compounds of specifically endophytic origin are not explored against SARS-CoV2. In the current study 45 compounds that have been reported active against viruses such as influenza, H1N1, HIV, HCV, hCMV, and EV-71 were retrieved through literature and screen them through rigorous computation workflow. Top compounds obtained after docking and MM-GBSA analysis for each protease (PLpro and Mpro) are known to have antiviral activity against different virus. Top ligands for both the proteins in present study, Cytonic acids $A$ and $B$ are known to possess in vitro inhibitory activities towards hCMV protease with the $\mathrm{IC}_{50}$ values of $43 \mu \mathrm{mol}$ and $11 \mu \mathrm{mol}$, respectively. Both the Cytonic acids were extracted from the fermented culture of endophytic fungus Cytonaema sp., which was isolated from the plant Quercus sp. (European oak) ${ }^{60}$. Other compounds interacting with Mpro are Asperphenalenone $A$ and Asperphenalenone $D$, which were obtained from the ethyl acetate fraction of fermented culture of Aspergillus sp., an endophytic fungus isolated from plant Kadsura longipedunculata. Asperphenalenone A and D were displayed anti-HIV activity with $\mathrm{IC}_{50}$ S of 4.5 and $2.4 \mu \mathrm{M}$, respectively ${ }^{32}$. Aspergilline $\mathrm{E}$ was extracted along with Aspergillines A-D from Aspergillus versicolor, an endophyte isolated from plant Paris polyphylla var. yunnanensis, collected from China. Aspergilline E showed weak antiviral activity towards Tobacco mosaic virus with $\mathrm{IC}_{50}$ of $33.6 \pm 3.0 \mu \mathrm{M}^{27}$. In present study it interacts with the PLpro with multiple interaction types. Another compound having strong interaction with PLpro is 4-dehydroxyaltersolanol $A$, which was obtained from endophytic fungus Nigrospora sp. YE3033, harboured in Aconitum carmichaeli. 4- 
541 dehydroxyaltersolanol A displayed in vitro antiviral activity towards $\mathrm{H} 1 \mathrm{~N} 1$ influenza $A$ with $\mathrm{IC}_{50}$ 542 of $8.35 \pm 1.41 \mu \mathrm{g} / \mathrm{mL}^{22}$.

543 Cytonic acid A and Cytonic acid B are two best docked compound and their strong 544 interactions with both the proteases, PLpro and Mpro, are also shown through MD simulation 545 study. In view of unavailability of medication for corona virus infection, present study proposes 546 Cytonic acids $A$ and $B$ as the dual inhibitor that interact with crucial amino acids of binding site 547 of PLpro and Mpro to inhibit their function and can be beneficial in forthcoming in vitro and in 548 vivo studies for COVID-19 therapeutics. In vitro validation of the proposed compounds 549 necessitates the utilization of Biosafety Level 4 (BSL4) as we are dealing with infecting agents, 550 only in silico study has been carried out. Data represented in this study, will be helpful to the 551 people with such facility to validated in silico finding. 


\section{References}

1. Shukla, A. et al. Curse of La Corona: unravelling the scientific and psychological conundrums of the 21st century pandemic. Mol. Divers. (2021) doi:10.1007/s11030020-10167-2.

2. Fakhar, Z., Khan, S., AlOmar, S. Y., Alkhuriji, A. \& Ahmad, A. ABBV-744 as a potential inhibitor of SARS-CoV-2 main protease enzyme against COVID-19. Sci. Rep. 11, 1-15 (2021).

3. Filsinger, M., Freitag, M., Erhardt, J. \& Wamsler, S. Rally around your fellows: Information and social trust in a real-world experiment during the corona crisis. https://doi.org/10.1080/03623319.2021.19544631-15 (2021) doi:10.1080/03623319.2021.1954463.

4. Forni, G. et al. COVID-19 vaccines: where we stand and challenges ahead. Cell Death Differ. 28, 626-639 (2021).

5. Kyriakidis, N. C., López-Cortés, A., González, E. V., Grimaldos, A. B. \& Prado, E. O. SARS-CoV-2 vaccines strategies: a comprehensive review of phase 3 candidates. npj Vaccines 6, (2021).

6. Zahid, M. N., Moosa, M. S., Perna, S. \& Buti, E. Bin. A review on COVID-19 vaccines: stages of clinical trials, mode of actions and efficacy. Arab J. Basic Appl. Sci. 28, 225233 (2021).

7. Kannan, S. R. et al. Evolutionary analysis of the delta and Delta Plus variants of the SARS-CoV-2 viruses. J. Autoimmun. 124, 102715 (2021).

8. Wang, P. et al. Antibody resistance of SARS-CoV-2 variants B.1.351 and B.1.1.7. Nature 593, 130-135 (2021).

9. Thomford, N. E. et al. Natural products for drug discovery in the 21st century: Innovations for novel drug discovery. Int. J. Mol. Sci. 19, (2018).

10. Messaoudi, O. et al. Berries anthocyanins as potential SARS-CoV-2 inhibitors targeting the viral attachment and replication; molecular docking simulation. Egypt. J. Pet. 30, 33-43 (2021).

11. Rao, P. et al. Proposing a fungal metabolite-flaviolin as a potential inhibitor of 3CLpro of novel coronavirus SARS-CoV-2 identified using docking and molecular dynamics. J. Biomol. Struct. Dyn. (2020) doi:10.1080/07391102.2020.1813202.

12. Rao, P. et al. Identifying structural - functional analogue of GRL0617, the only well - 
established inhibitor for papain - like protease ( PLpro ) of SARS - CoV2 from the pool of fungal metabolites using docking and molecular dynamics simulation. Mol. Divers. (2021) doi:10.1007/s11030-021-10220-8.

13. Prajapati, J., Patel, R., Goswami, D., Saraf, M. \& Rawal, R. M. Sterenin M as a potential inhibitor of SARS-CoV-2 main protease identified from MeFSAT database using molecular docking, molecular dynamics simulation and binding free energy calculation. Comput. Biol. Med. 104568 (2021) doi:10.1016/j.compbiomed.2021.104568.

14. Arora, D. et al. Isolation and characterization of bioactive metabolites from Xylaria psidii, an endophytic fungus of the medicinal plant Aegle marmelos and their role in mitochondrial dependent apoptosis against pancreatic cancer cells. Phytomedicine 23, 1312-1320 (2016).

15. Hawas, U. W., El-Beih, A. A. \& El-Halawany, A. M. Bioactive anthraquinones from endophytic fungus aspergillus versicolor isolated from red sea algae. Arch. Pharm. Res. 35, 1749-1756 (2012).

16. Yang, Z. J. et al. New azaphilones, phomopsones A-C with biological activities from an endophytic fungus Phomopsis sp. CGMCC No.5416. Fitoterapia 145, 104573 (2020).

17. Hawas, U. W., Al-Farawati, R., El-Kassem, L. T. A. \& Turki, A. J. Different culture metabolites of the Red Sea fungus Fusarium equiseti optimize the inhibition of hepatitis C virus NS3/4A protease (HCV PR). Mar. Drugs 14, (2016).

18. Arunpanichlert, J. et al. Azaphilone and Isocoumarin Derivatives from the Endophytic Fungus Penicillium sclerotiorum PSU-A13. Chem. Pharm. Bull 58, 1033-1036 (2010).

19. Kumar, B. K. et al. Pharmacophore based virtual screening, molecular docking, molecular dynamics and MM-GBSA approach for identification of prospective SARSCoV-2 inhibitor from natural product databases. J. Biomol. Struct. Dyn. 0, 1-24 (2020).

20. Rao, P. et al. Identifying structural-functional analogue of GRL0617, the only wellestablished inhibitor for papain-like protease (PLpro) of SARS-CoV2 from the pool of fungal metabolites using docking and molecular dynamics simulation. Mol. Divers. (2021) doi:10.1007/s11030-021-10220-8.

21. Fu, Z. et al. The complex structure of GRL0617 and SARS-CoV-2 PLpro reveals a hot spot for antiviral drug discovery. Nat. Commun. 2021 121 12, 1-12 (2021). 
22. Zhang, S. P. et al. Antiviral anthraquinones and azaphilones produced by an endophytic fungus Nigrospora sp. from Aconitum carmichaeli. Fitoterapia 112, 85-89 (2016).

23. Qin, C. et al. Sesquiterpenoids and xanthones derivatives produced by spongederived fungus Stachybotry sp. HH1 ZSDS1F1-2. J. Antibiot. Adv. online Publ. (2014) doi:10.1038/ja.2014.97.

24. Zhang, G. et al. Antiviral isoindolone derivatives from an endophytic fungus Emericella sp. associated with Aegiceras corniculatum. Phytochemistry 72, 14361442 (2011).

25. Liu, L. et al. Chloropupukeananin, the first chlorinated pupukeanane derivative, and its precursors from Pestalotiopsis fici. Org. Lett. 10, 1397-1400 (2008).

26. Zhang, D. et al. Periconiasin G, a new cytochalasan with unprecedented $7 / 6 / 5$ tricyclic ring system from the endophytic fungus Periconia sp. (2016) doi:10.1016/j.tetlet.2016.01.030.

27. Zhou, M. et al. Aspergillines A-E, Highly Oxygenated Hexacyclic Indole-Tetrahydrofuran-Tetramic Acid Derivatives from Aspergillus versicolor. (2014) doi:10.1021/ol502307u.

28. Guo, B. et al. Cytonic acids A and B: Novel tridepside inhibitors of hCMV protease from the endophytic fungus Cytonaema species. J. Nat. Prod. 63, 602-604 (2000).

29. Bashyal, B. P. et al. Altertoxins with potent anti-HIV activity from Alternaria tenuissima QUE1Se, a fungal endophyte of Quercus emoryi. Bioorganic Med. Chem. 22, 61126116 (2014).

30. Ding, L. et al. Xiamycin, a pentacyclic indolosesquiterpene with selective anti-HIV activity from a bacterial mangrove endophyte. Bioorganic Med. Chem. Lett. 20, 66856687 (2010).

31. Yu, G. et al. Neosartoryadins A and B, Fumiquinazoline Alkaloids from a MangroveDerived Fungus Neosartorya udagawae HDN13-313. Org. Lett. 18, 244-247 (2016).

32. Pang, X. et al. Metabolites from the Plant Endophytic Fungus Aspergillus sp. CPCC 400735 and Their Anti-HIV Activities. J. Nat. Prod. 80, 2595-2601 (2017).

33. Ding, J. et al. Microbial natural product alternariol 5-O-Methyl ether inhibits HIV-1 integration by blocking nuclear import of the pre-integration complex. Viruses $9,1-14$ (2017). 
34. Leach, A. R., Gillet, V. J., Lewis, R. A. \& Taylor, R. Three-dimensional pharmacophore methods in drug discovery. J. Med. Chem. 53, 539-558 (2010).

35. Sastry, G. M., Adzhigirey, M. \& Sherman, W. Protein and ligand preparation: parameters, protocols, and influence on virtual screening enrichments. J Comput Aided Mol Des 27, 221-234 (2013).

36. Wang, W., Donini, O., Reyes, C. M. \& Kollman, P. A. Biomolecular simulations: Recent developments in force fields, simulations of enzyme catalysis, protein-ligand, protein-protein, and protein-nucleic acid noncovalent interactions. Annual Review of Biophysics and Biomolecular Structure vol. 30 211-243 (2001).

37. Wang, J., Hou, T. \& Xu, X. Recent Advances in Free Energy Calculations with a Combination of Molecular Mechanics and Continuum Models. Curr. Comput. AidedDrug Des. 2, 287-306 (2006).

38. Kollman, P. A. et al. Calculating structures and free energies of complex molecules: Combining molecular mechanics and continuum models. Acc. Chem. Res. 33, 889897 (2000).

39. Massova, I. \& Kollman, P. A. Combined molecular mechanical and continuum solvent approach (MM- PBSA/GBSA) to predict ligand binding. Perspectives in Drug Discovery and Design vol. 18 113-135 (2000).

40. Pires, D. E. V., Blundell, T. L. \& Ascher, D. B. pkCSM: Predicting small-molecule pharmacokinetic and toxicity properties using graph-based signatures. J. Med. Chem. 58, 4066-4072 (2015).

41. Ren, Z. et al. The newly emerged SARS-Like coronavirus HCoV-EMC also has an 'Achilles" heel": Current effective inhibitor targeting a 3C-like protease'. Protein Cell 4, 248-250 (2013).

42. Kumar, A. et al. Computational and In-Vitro Validation of Natural Molecules as Potential Acetylcholinesterase Inhibitors and Neuroprotective Agents. Curr. Alzheimer Res. 16, 116-127 (2018).

43. Yang, H., Bartlam, M. \& Rao, Z. Drug Design Targeting the Main Protease, the Achilles Heel of Coronaviruses. Curr. Pharm. Des. 12, 4573-4590 (2006).

44. Zhou, P. et al. A pneumonia outbreak associated with a new coronavirus of probable bat origin. Nature 579, 270-273 (2020).

45. Huang, C. et al. Clinical features of patients infected with 2019 novel coronavirus in 
Wuhan, China. Lancet 395, 497-506 (2020).

682

683

684

685

686

687

688

689

690

691

692

693

694

695

696

697

698

699

700

701

702

703

704

705

706

707

708

709

710

711

712

46. Poustforoosh, A. et al. Evaluation of potential anti-RNA-dependent RNA polymerase (RdRP) drugs against the newly emerged model of COVID-19 RdRP using computational methods. Biophys. Chem. 272, 106564 (2021).

47. Patel, C. N., Kumar, S. P., Pandya, H. A. \& Rawal, R. M. Identification of potential inhibitors of coronavirus hemagglutinin-esterase using molecular docking, molecular dynamics simulation and binding free energy calculation. Mol. Divers. 25, 421-433 (2021).

48. Guedes, I. A. et al. Drug design and repurposing with DockThor-VS web server focusing on SARS-CoV-2 therapeutic targets and their non-synonym variants. Sci. Rep. 11, 1-20 (2021).

49. Basu, A., Sarkar, A. \& Maulik, U. Molecular docking study of potential phytochemicals and their effects on the complex of SARS-CoV2 spike protein and human ACE2. Sci. Rep. 10, 1-15 (2020).

50. Murugan, N. A., Kumar, S., Jeyakanthan, J. \& Srivastava, V. Searching for targetspecific and multi-targeting organics for Covid-19 in the Drugbank database with a double scoring approach. Sci. Rep. 10, 1-16 (2020).

51. Rao, P. et al. Reckoning a fungal metabolite, Pyranonigrin A as a potential Main protease (Mpro) inhibitor of novel SARS-CoV-2 virus identified using docking and molecular dynamics simulation. Biophys. Chem. 264, 106425 (2020).

52. Jiménez-Avalos, G. et al. Comprehensive virtual screening of $4.8 \mathrm{k}$ flavonoids reveals novel insights into allosteric inhibition of SARS-CoV-2 MPRO. Sci. Reports 2021111 11, 1-19 (2021).

53. Yoshino, R., Yasuo, N. \& Sekijima, M. Identification of key interactions between SARS-CoV-2 main protease and inhibitor drug candidates. Sci. Reports 202010110 , $1-8$ (2020).

54. Keretsu, S., Bhujbal, S. P. \& Cho, S. J. Rational approach toward COVID-19 main protease inhibitors via molecular docking, molecular dynamics simulation and free energy calculation. Sci. Reports $202010110,1-14$ (2020).

55. Komatsu, T. S. et al. Drug binding dynamics of the dimeric SARS-CoV-2 main protease, determined by molecular dynamics simulation. Sci. Reports 202010110 , 1-11 (2020). 
56. Mukherjee, S., Dasgupta, S., Adhikary, T., Adhikari, U. \& Panja, S. S. Structural insight to hydroxychloroquine-3C-like proteinase complexation from SARS-CoV-2: inhibitor modelling study through molecular docking and MD-simulation study. J. Biomol. Struct. Dyn. 1-13 (2020) doi:10.1080/07391102.2020.1804458.

57. Parmar, P. et al. The rise of gingerol as anti-QS molecule: Darkest episode in the LuxR-mediated bioluminescence saga. Bioorg. Chem. 99, 103823 (2020).

58. Pandya, P. N. et al. Identification of promising compounds from curry tree with cyclooxygenase inhibitory potential using a combination of machine learning, molecular docking, dynamics simulations and binding free energy calculations. Mol. Simul. 46, 812-822 (2020).

59. Manganyi, M. C. \& Ateba, C. N. Untapped potentials of endophytic fungi: A review of novel bioactive compounds with biological applications. Microorganisms 8, 1-25 (2020).

60. Guo, B. et al. Cytonic acids A and B: Novel tridepside inhibitors of hCMV protease from the endophytic fungus Cytonaema species. J. Nat. Prod. 63, 602-604 (2000). 


\section{Acknowledgements}

731 We acknowledge Education Department, Government of Gujarat, India for the providing 732 research fellowship to Rohit Patel and Priyashi Rao under the ScHeme Of Developing High 733 quality research (SHODH), and University Grants Commission (UGC), New Delhi, India for 734 providing the fellowship for the award of 'CSIR-NET Junior Research Fellowship (JRF)' to 735 Jignesh Prajapati. Authors are thankful to Department of Microbiology and Biotechnology, 736 School of Sciences, Gujarat University, DST-FIST Sponsored Department, for providing 737 necessary facilities to perform experiments. We acknowledge GSBTM, DST, Government of 738 Gujarat for providing Bioinformatics Node facility and Finishing School support. We acknowledge GUJCOST, DST, Government of Gujarat for Super-computing facility provision.

740

741 Author contributions

742 J.P. and D.G. conceived designed the experiments; J.P., R.P, and P.R. performed the 743 experiments; J.P., R.P, and D.G. analyzed the data and wrote the manuscript; R.R, and M.S. 744 supervised the research and revised the manuscript.

745

\section{Conflicts of interest}

747

It is declared that the authors have no conflict of interest in the publication of this article.

\section{Funding sources}

750 This research did not receive any specific grant from funding agencies in the public, 751 commercial, or not-for-profit sectors. 




Figure 1 Representation for addressing role of viral proteases PLpro and Mpro to produce non-structural proteins participating in viral replication and transcription. 

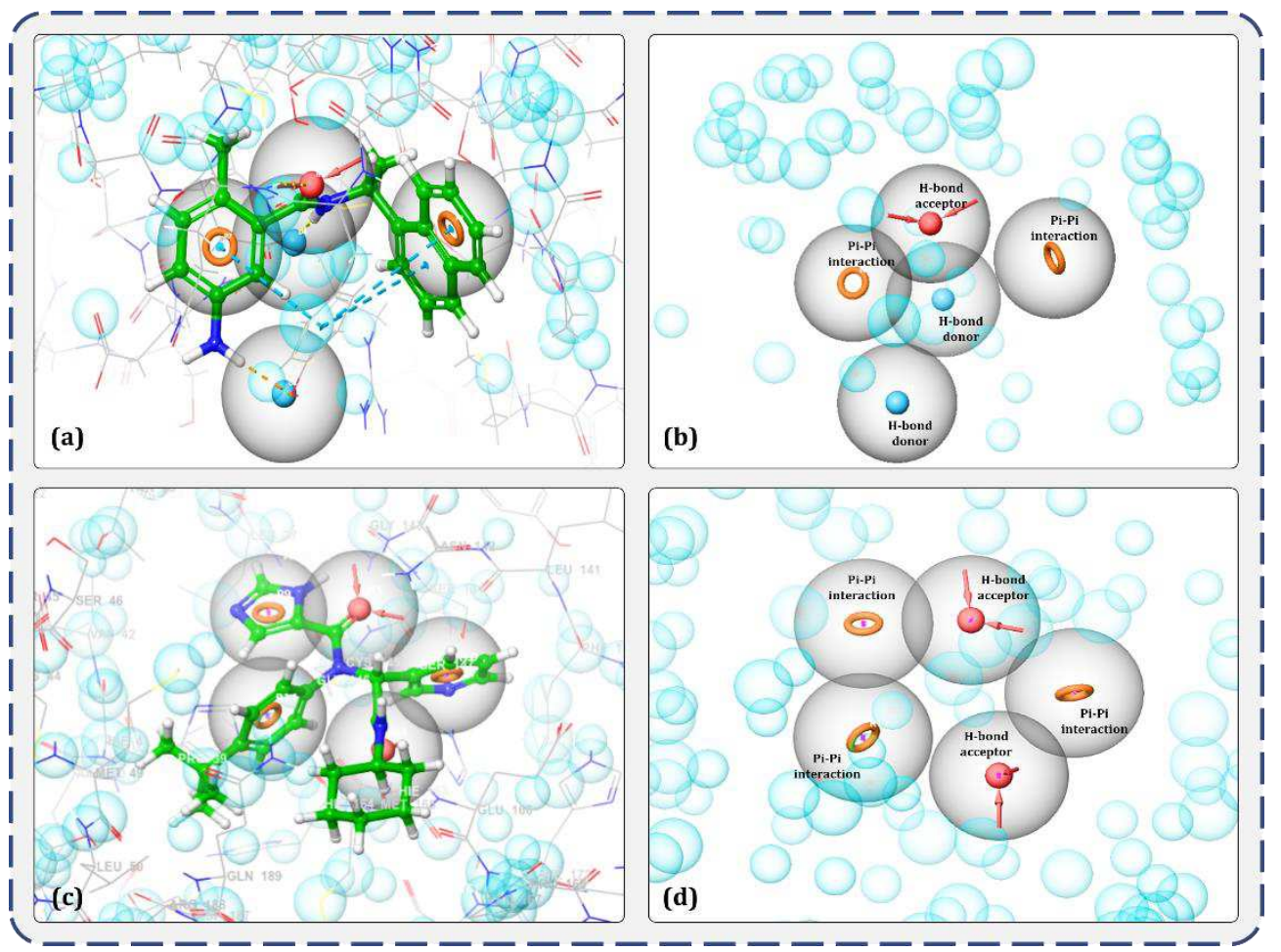

Figure 2 Illustration of E-pharmacophore features of receptor-ligand complex; (a) representative features important in binding of GRL0617 ligand with receptor PLpro and, (b) type of pharmacophore features significant for interaction with PLpro, (c) representative

763 features important in binding of X77 ligand with receptor Mpro and, (b) type of pharmacophore features significant for interaction with Mpro. 

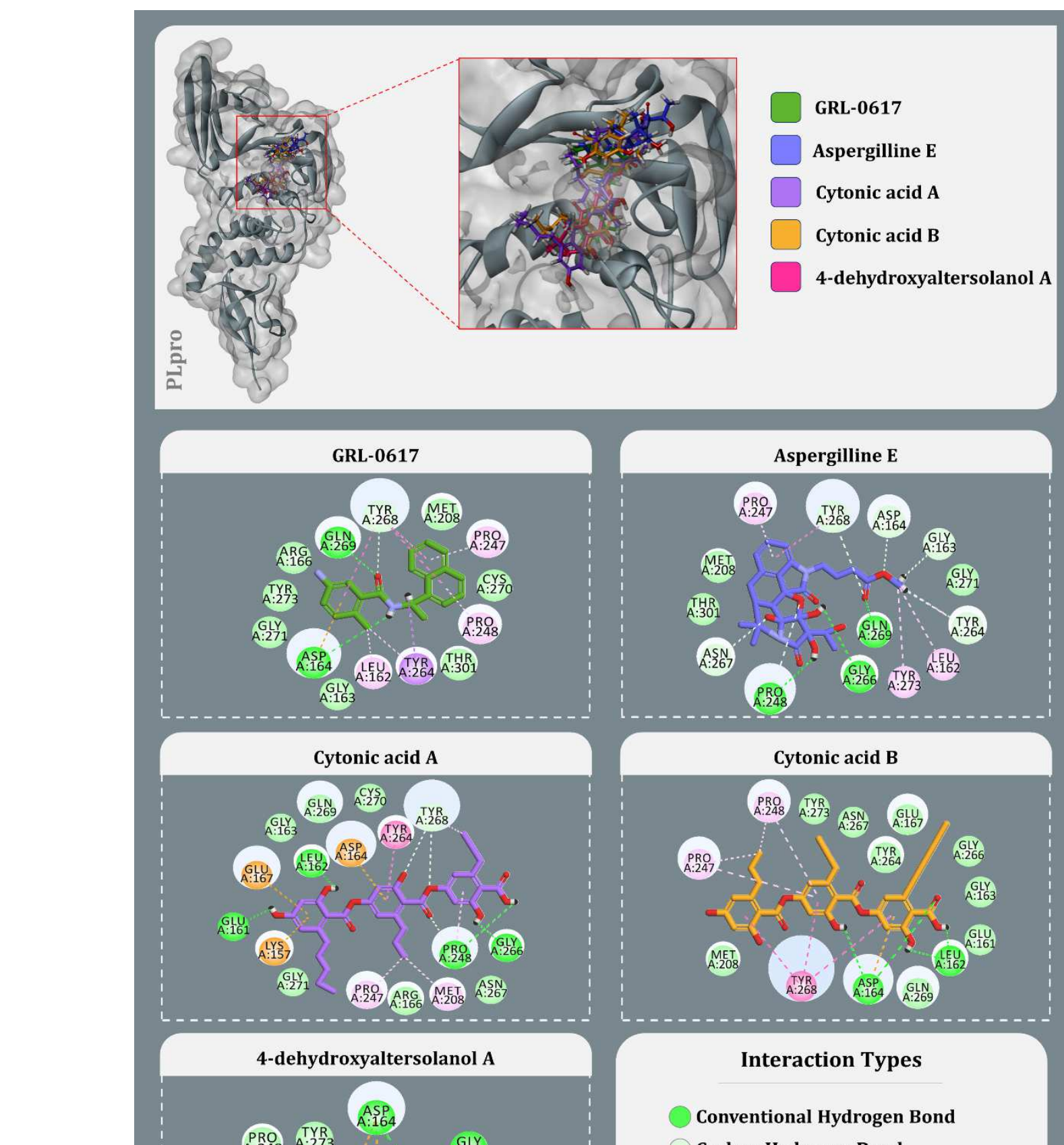

Figure 3 Interaction profile of GRL0617 and best docked four antiviral compounds with SARSCoV2-PLpro (Amino acids without any bond interactions are interacting with Van der Waals forces). 


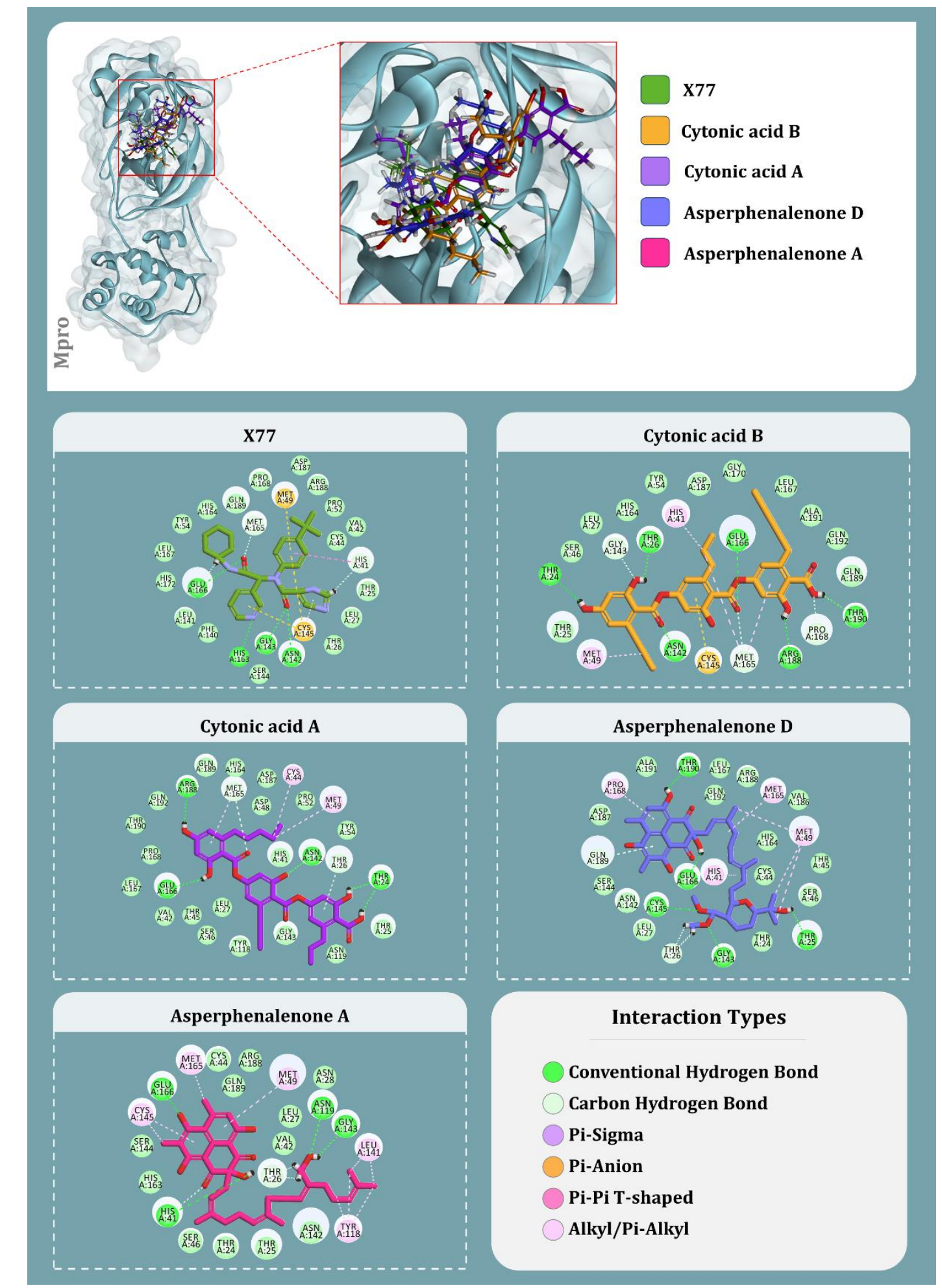

Figure 4 Interaction profile of $X 77$ and best docked four antiviral compounds with SARSCoV2-Mpro (Amino acids without any bond interactions are interacting with Van der Waals forces). 




Figure $5 \mathrm{MD}$ simulation Protein-ligand interaction root-mean-square deviation (RMSD) profile of SARS-CoV2-PLpro-Cytonic acid A, SARS-CoV2-PLpro- Cytonic acid B and SARS-CoV2PLpro-GRL0617. 
Lig fit Prot Protein backbone Lig fit Lig
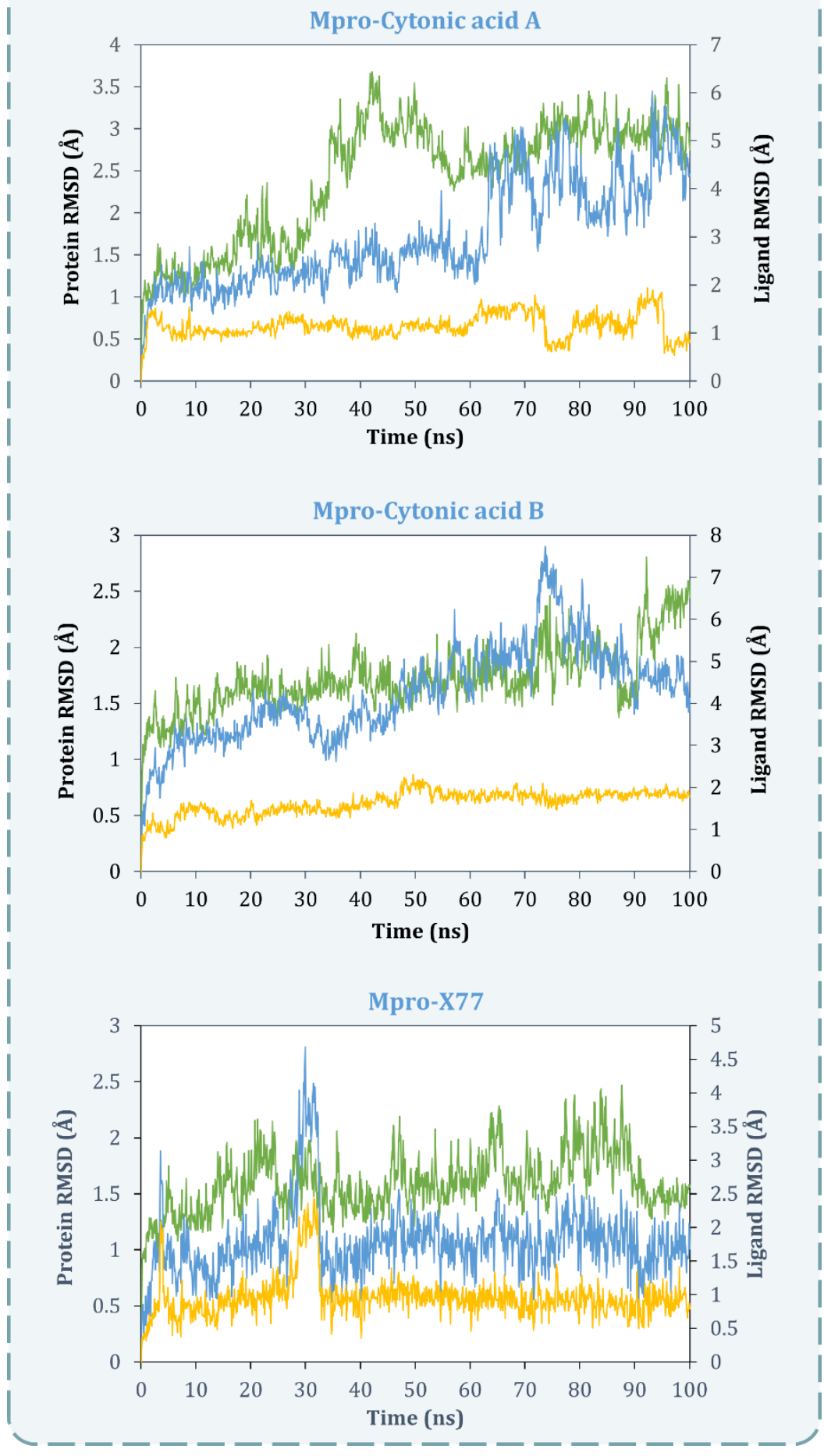

Figure 6 MD simulation Protein-ligand interaction root-mean-square deviation (RMSD) profile of SARS-CoV2-Mpro-Cytonic acid A, SARS-CoV2-Mpro- Cytonic acid B and SARS-CoV2Mpro-X77. 


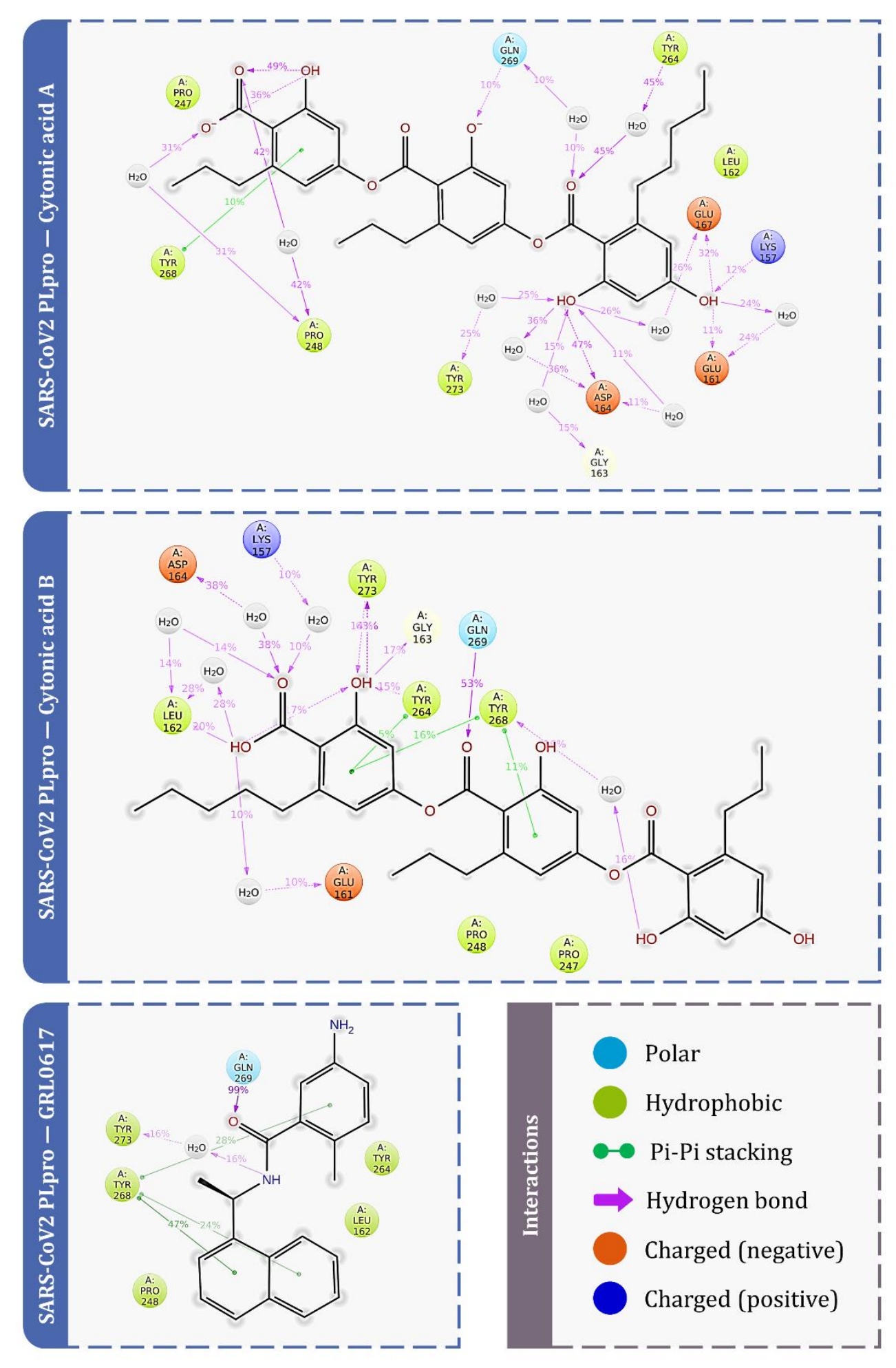

Figure 7 Protein-Ligand interaction diagram for PLpro showing percent of total time involved 792 for particular interaction during molecular dynamics. 




Figure 8 Protein-Ligand interaction diagram for Mpro showing percent of total time involved for particular interaction during molecular dynamics. 
Water bridges

Hydrogen bonds

Hydrophobic

Ionic



$-$

4

1.4

1.2
1.0

ज 0.8

ᄃ 0.6

\begin{tabular}{l|l}
0.6 \\
0.4
\end{tabular}

- 0.2

$+0.0$

ס

$\sigma$

- 1.4

(1) 1.2

$+\quad 1.0$

ᄃ 0.8

\begin{tabular}{l|l}
-0.6 \\
0.4
\end{tabular}

0.4

0.0

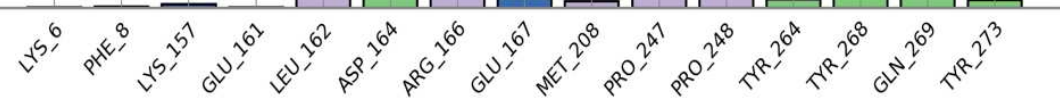

Figure 9 Protein-Ligand interaction diagram showing interaction fraction of crucial interacting 


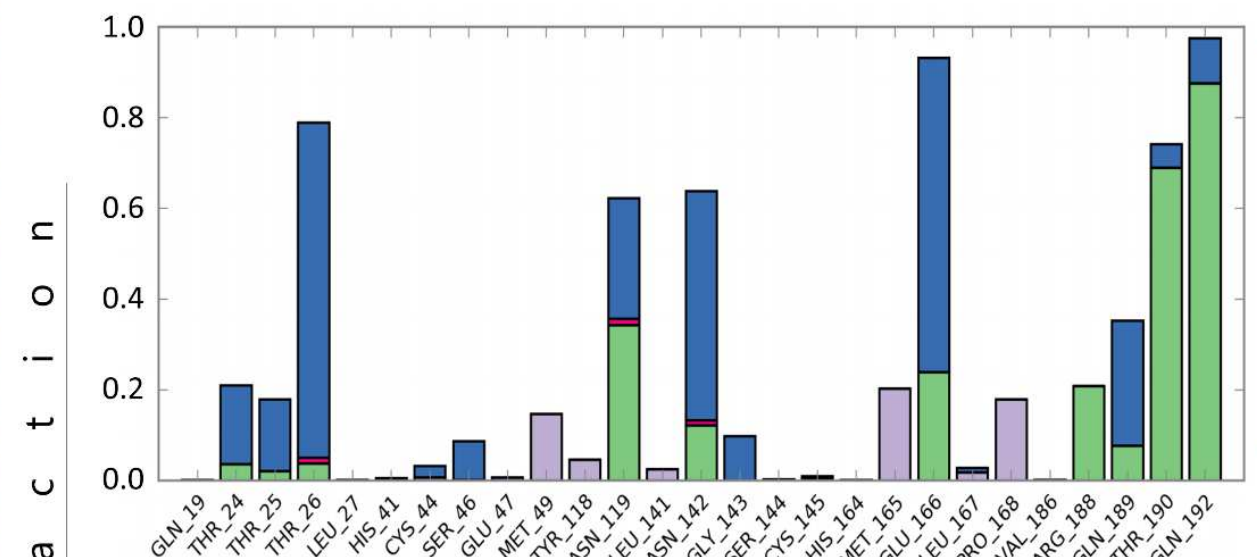

Figure 10 Protein-Ligand interaction diagram showing interaction fraction of crucial interacting amino acids of Mpro. 




806 Figure 11 Timeline representation of the interactions of ligand with amino acids for the 807 complex SARS-CoV2-PLpro-Cytonic acid A, SARS-CoV2-PLpro- Cytonic acid B and SARS808 CoV2-PLpro-GRL0617. 


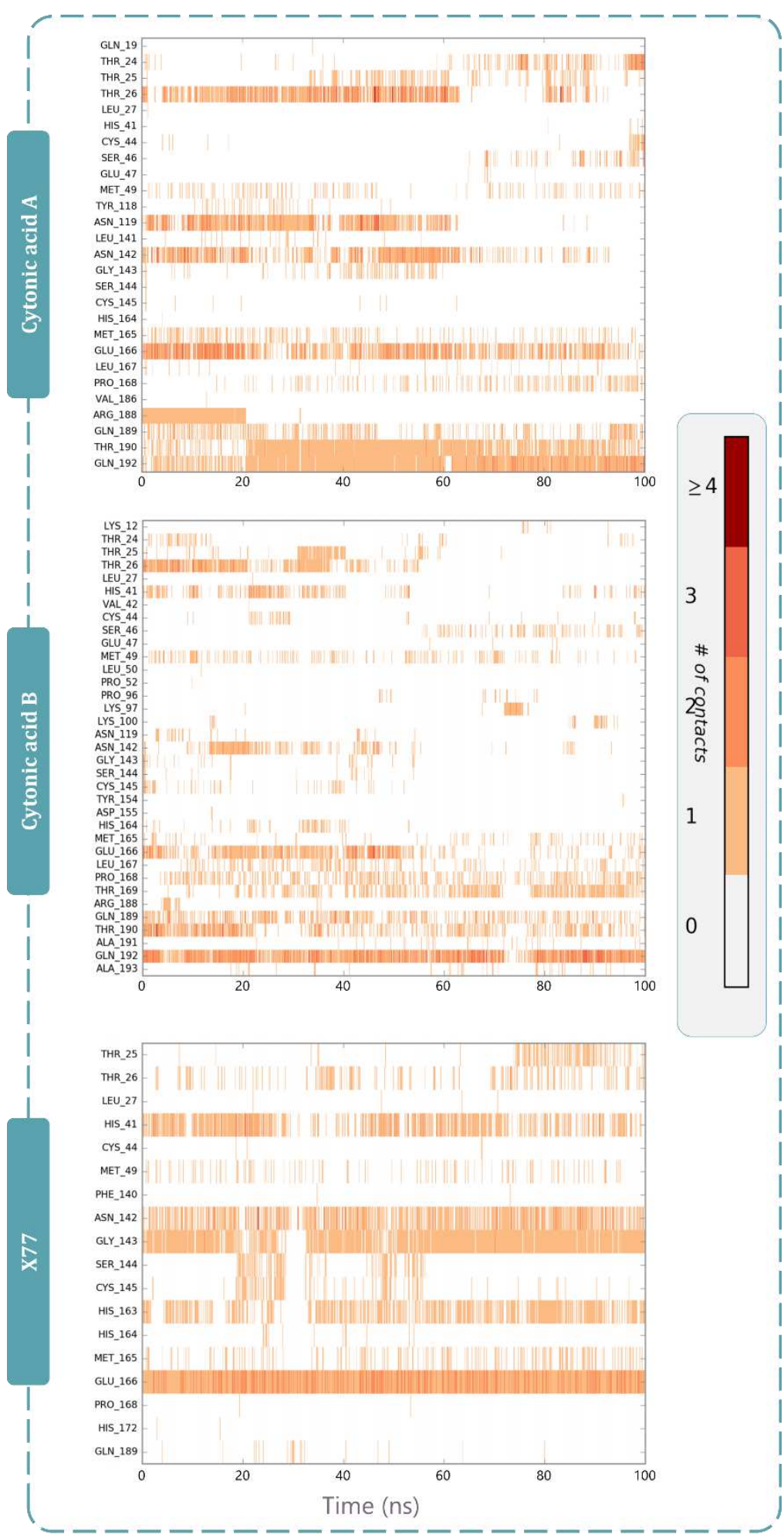

811 Figure 12 Timeline representation of the interactions of ligand with amino acids for the 812 complex SARS-CoV2-Mpro-Cytonic acid A, SARS-CoV2-Mpro- Cytonic acid B and SARS813 CoV2-Mpro-X77. 
Tables

Table 1 List of antiviral compounds the endophytes with its Metadata

\begin{tabular}{|c|c|c|c|c|c|c|c|}
\hline $\begin{array}{l}\text { Sr. } \\
\text { No. }\end{array}$ & Secondary metabolite & $\begin{array}{l}\text { Endophytic } \\
\text { organism }\end{array}$ & Host & Location & Virus & Activity $\left(\mathrm{IC}_{50}\right)$ & Reference \\
\hline 1. & $\begin{array}{c}\text { 6-O-demethyl-4- } \\
\text { dehydroxyaltersolanol A }\end{array}$ & \multirow{4}{*}{$\begin{array}{l}\text { Nigrospora sp. } \\
\text { YE3033 }\end{array}$} & \multirow{4}{*}{$\begin{array}{l}\text { Aconitum } \\
\text { carmichaeli }\end{array}$} & \multirow{4}{*}{ China } & \multirow{4}{*}{$\begin{array}{c}\mathrm{H} 1 \mathrm{~N} 1 \\
\text { influenza } \mathrm{A}\end{array}$} & $\begin{array}{c}2.59 \pm 1.22 \\
\mu \mathrm{g} / \mathrm{mL}\end{array}$ & \multirow{4}{*}{22} \\
\hline 2. & 4-dehydroxyaltersolanol A & & & & & $\begin{array}{c}8.35 \pm 1.41 \\
\mu \mathrm{g} / \mathrm{mL}\end{array}$ & \\
\hline 3. & Altersolanol B & & & & & $\begin{array}{c}7.82 \pm 1.86 \\
\mu \mathrm{g} / \mathrm{mL}\end{array}$ & \\
\hline 4. & Chermesinone B & & & & & $\begin{array}{c}0.80 \pm 0.29 \\
\mu \mathrm{g} / \mathrm{mL}\end{array}$ & \\
\hline 5. & Emodin & $\begin{array}{l}\text { Aspergillus } \\
\text { versicolor }\end{array}$ & Halimeda opuntia & Egypt & $\begin{array}{c}\mathrm{HCV} \\
\text { Protease } \\
\end{array}$ & $\begin{array}{c}22.5 \pm 1.6 \\
\mu \mathrm{g} / \mathrm{mL}\end{array}$ & 15 \\
\hline 6. & $\omega$-hydroxyemodin & Fusarium equiseti & Padina pavonica & Egypt & $\begin{array}{c}\mathrm{HCV} \\
\text { Protease } \\
\end{array}$ & $\begin{array}{c}10.71 \pm 2.3 \\
\mu \mathrm{M}\end{array}$ & 17 \\
\hline \multirow{2}{*}{7.} & \multirow{2}{*}{$(+)$-Sclerotiorin } & \multirow{2}{*}{$\begin{array}{c}\text { Penicillium } \\
\text { sclerotiorum PSU- } \\
\text { A13 }\end{array}$} & \multirow{2}{*}{ Garcinia atroviridis } & \multirow{2}{*}{ Thailand } & $\begin{array}{c}\text { HIV-1 } \\
\text { Integrase }\end{array}$ & $14.5 \mu \mathrm{g} / \mathrm{mL}$ & \multirow{2}{*}{18} \\
\hline & & & & & $\begin{array}{l}\text { HIV-1 } \\
\text { Protease }\end{array}$ & $62.7 \mu \mathrm{g} / \mathrm{mL}$ & \\
\hline 8. & Cordycepin & \multirow{8}{*}{ Fusarium equiseti } & \multirow{8}{*}{ Padina pavonica } & \multirow{8}{*}{ Egypt } & \multirow{8}{*}{$\begin{array}{l}\mathrm{HCV} \\
\text { Protease }\end{array}$} & $22.3 \mu \mathrm{M}$ & \multirow{8}{*}{17} \\
\hline 9. & Ara-A & & & & & $24.5 \mu \mathrm{M}$ & \\
\hline 10. & $\begin{array}{l}\text { Cyclic tetrapeptidecyclo- } \\
\text { [Phenyl alanyl-pro-leu-pro] }\end{array}$ & & & & & $29.4 \mu \mathrm{M}$ & \\
\hline 11. & $\begin{array}{l}\text { 17-demethyl-2,11-dideoxy- } \\
\text { rhizoxin }\end{array}$ & & & & & $29.4 \mu \mathrm{M}$ & \\
\hline 12. & $\begin{array}{l}\text { 5-chloro-3,6-dihydroxy-2- } \\
\text { methyl-1,4-benzoquinone }\end{array}$ & & & & & $34.4 \mu \mathrm{M}$ & \\
\hline 13. & Perlolyrine & & & & & $35.1 \mu \mathrm{M}$ & \\
\hline 14. & Cyclo (L-Pro-L-Val) & & & & & $23.2 \mu \mathrm{M}$ & \\
\hline 15. & Griseoxanthone C & & & & & $19.8 \mu \mathrm{M}$ & \\
\hline
\end{tabular}




\begin{tabular}{|c|c|c|c|c|c|c|c|}
\hline 16. & Stachybogrisephenone B & \multirow{3}{*}{$\begin{array}{l}\text { Stachybotry sp. } \\
\text { HH1 ZDDS1F1-2 }\end{array}$} & \multirow{3}{*}{ Sponge } & \multirow{3}{*}{ China } & \multirow{3}{*}{ EV71 } & $30.1 \mu \mathrm{M}$ & \multirow{3}{*}{23} \\
\hline 17. & Grisephenone A & & & & & $50.0 \mu \mathrm{M}$ & \\
\hline 18. & $\begin{array}{c}\text { 3,6,8- Trihydroxy-1- } \\
\text { methylxanthine }\end{array}$ & & & & & $40.3 \mu \mathrm{M}$ & \\
\hline 19. & Emerimidine A & \multirow{2}{*}{$\begin{array}{c}\text { Emericella sp. (HK- } \\
\text { ZJ) }\end{array}$} & \multirow{2}{*}{ Aegiceras corniculatum } & \multirow{2}{*}{ China } & \multirow{2}{*}{$\begin{array}{c}\mathrm{H} 1 \mathrm{~N} 1 \\
\text { influenza } \mathrm{A}\end{array}$} & $42.07 \mu \mathrm{g} / \mathrm{mL}$ & \multirow{2}{*}{24} \\
\hline 20. & Emerimidine B & & & & & $62.05 \mu \mathrm{g} / \mathrm{mL}$ & \\
\hline 21. & Chloropupukeananin & Pestalotiopsis fici & Unknown & China & HIV-1 & $14.6 \mu \mathrm{M}$ & 25 \\
\hline 22. & Periconiasin $\mathrm{G}$ & Periconia sp. F-31 & Annona muricata & China & HIV-1 & $67.0 \mu \mathrm{M}$ & 26 \\
\hline 23. & Aspergilline $A$ & \multirow{5}{*}{$\begin{array}{l}\text { Aspergillus } \\
\text { versicolor }\end{array}$} & \multirow{5}{*}{$\begin{array}{c}\text { Paris polyphylla var. } \\
\text { yunnanensis }\end{array}$} & \multirow{5}{*}{ China } & \multirow{5}{*}{$\begin{array}{l}\text { Tobacco } \\
\text { mosaic virus }\end{array}$} & $56.4 \pm 3.8 \mu \mathrm{M}$ & \multirow{5}{*}{27} \\
\hline 24. & Aspergilline B & & & & & $47.3 \pm 3.2 \mu \mathrm{M}$ & \\
\hline 25. & Aspergilline C & & & & & $35.6 \pm 2.8 \mu \mathrm{M}$ & \\
\hline 26. & Aspergilline D & & & & & $38.9 \pm 3.5 \mu \mathrm{M}$ & \\
\hline 27. & Aspergilline $\mathrm{E}$ & & & & & $33.6 \pm 3.0 \mu \mathrm{M}$ & \\
\hline 28. & Cytonic acid A & \multirow{2}{*}{$\begin{array}{c}\text { Cytonaema sp. } \\
\text { F32027 }\end{array}$} & \multirow{2}{*}{ Quercus sp. } & \multirow{2}{*}{ U. K } & \multirow{2}{*}{$\begin{array}{c}\text { CMV } \\
\text { Protease }\end{array}$} & $43 \mu \mathrm{M}$ & \multirow{2}{*}{28} \\
\hline 29. & Cytonic acid B & & & & & $11 \mu \mathrm{M}$ & \\
\hline 30. & Phomopsone B & \multirow{2}{*}{$\begin{array}{l}\text { Phomopsis sp. } \\
\text { CGMCC No.5416 }\end{array}$} & \multirow{2}{*}{ Achyranthes bidentata } & \multirow{2}{*}{ China } & \multirow{2}{*}{ HIV-1 } & $7.6 \mu \mathrm{M}$ & \multirow{2}{*}{16} \\
\hline 31. & Phomopsone C & & & & & $0.5 \mu \mathrm{M}$ & \\
\hline 32. & Altertoxin V & \multirow{3}{*}{$\begin{array}{c}\text { Alternaria } \\
\text { tenuissima } \\
\text { QUE1Se }\end{array}$} & \multirow{3}{*}{ Quercus emoryi } & \multirow{3}{*}{ USA } & \multirow{3}{*}{ HIV-1 } & $0.09 \mu \mathrm{M}$ & \multirow{3}{*}{29} \\
\hline 33. & Altertoxin I & & & & & $1.42 \mu \mathrm{M}$ & \\
\hline 34. & Altertoxin II & & & & & $0.21 \mu \mathrm{M}$ & \\
\hline
\end{tabular}




\begin{tabular}{|c|c|c|c|c|c|c|c|}
\hline 35. & Altertoxin III & & & & & $0.29 \mu \mathrm{M}$ & \\
\hline 36. & Xiamycin & \multirow{2}{*}{$\begin{array}{c}\text { Streptomyces sp. } \\
\text { GT2002/1503 }\end{array}$} & \multirow{2}{*}{ Bruguiera gymnorrhiza } & \multirow{2}{*}{ Germany } & \multirow{2}{*}{ HIV-1 } & NA & \multirow{2}{*}{30} \\
\hline 37. & $\begin{array}{l}\text { Xiamycin methyl } \\
\text { ester }\end{array}$ & & & & & NA & \\
\hline 38. & Neosartoryadin A & \multirow{2}{*}{$\begin{array}{c}\text { Neosartorya } \\
\text { udagawae HDN13- } \\
313\end{array}$} & \multirow{2}{*}{ Aricennia marina } & \multirow{2}{*}{ China } & \multirow{2}{*}{$\begin{array}{c}\text { H1N1 } \\
\text { influenza A }\end{array}$} & $66 \mu \mathrm{M}$ & \multirow{2}{*}{31} \\
\hline 39. & Neosartoryadin B & & & & & $58 \mu \mathrm{M}$ & \\
\hline 40. & Asperphenalenone A & \multirow{4}{*}{$\begin{array}{l}\text { Aspergillus sp. } \\
\text { CPCC } 400735\end{array}$} & \multirow{4}{*}{$\begin{array}{c}\text { Kadsura } \\
\text { longipedunculata }\end{array}$} & \multirow{4}{*}{ China } & \multirow{4}{*}{ HIV-1 } & $4.5 \mu \mathrm{M}$ & \multirow{4}{*}{32} \\
\hline 41. & Asperphenalenone D & & & & & $2.4 \mu \mathrm{M}$ & \\
\hline 42. & Cytochalasin Z8 & & & & & $9.2 \mu \mathrm{M}$ & \\
\hline 43. & Epicocconigrone A & & & & & $6.6 \mu \mathrm{M}$ & \\
\hline 44. & Alternariol 5-o-methyl ether & Colletotrichum sp. & NA & China & HIV-1 & NA & 33 \\
\hline 45. & 8-Methyl emodin & $\begin{array}{l}\text { Aspergillus } \\
\text { versicolor }\end{array}$ & Halimeda opuntia & Egypt & $\begin{array}{c}\mathrm{HCV} \\
\text { Protease }\end{array}$ & $\begin{array}{c}40.2 \pm 2.3 \\
\mu \mathrm{g} / \mathrm{mL}\end{array}$ & 15 \\
\hline
\end{tabular}

$\mathrm{NA}=$ Not Available 
Table 2 Compounds managed to pass PLpro-GRL0167 complex pharmacophore hypothesis using Phase virtual screening

\begin{tabular}{|c|c|c|c|c|}
\hline Entry & Compound name & $\begin{array}{l}\text { Number } \\
\text { of Sites } \\
\text { Matched }\end{array}$ & Matched Ligand Sites & $\begin{array}{c}\text { Phase } \\
\text { Screen } \\
\text { Score }\end{array}$ \\
\hline 1 & Stachybogrisephenone B & 4 & $A(3) D(7) D(8) R(14) R(-)$ & 1.766 \\
\hline 2 & 4-dehydroxyaltersolanol $\mathrm{A}$ & 4 & $A(5) D(10) D(9) R(13) R(-)$ & 1.723 \\
\hline 3 & Aspergilline D & 4 & $\mathrm{~A}(3) \mathrm{D}(10) \mathrm{D}(11) \mathrm{R}(-) \mathrm{R}(17)$ & 1.717 \\
\hline 4 & Altersolanol B & 4 & $A(4) D(9) D(8) R(11) R(-)$ & 1.669 \\
\hline 5 & Aspergilline $\mathrm{E}$ & 4 & $A(3) D(12) D(13) R(-) R(20)$ & 1.513 \\
\hline 6 & Cytonic acid B & 4 & $A(4) D(12) D(-) R(21) R(20)$ & 1.436 \\
\hline 7 & Perlolyrine & 4 & $\mathrm{~A}(1) \mathrm{D}(-) \mathrm{D}(4) \mathrm{R}(6) \mathrm{R}(9)$ & 1.435 \\
\hline 8 & Neosartoryadin A & 4 & $\mathrm{~A}(3) \mathrm{D}(-) \mathrm{D}(8) \mathrm{R}(12) \mathrm{R}(11)$ & 1.434 \\
\hline 9 & Asperphenalenone D & 4 & $\mathrm{~A}(7) \mathrm{D}(13) \mathrm{D}(12) \mathrm{R}(23) \mathrm{R}(-)$ & 1.419 \\
\hline 10 & Cordycepin & 4 & $A(4) D(8) D(7) R(-) R(12)$ & 1.400 \\
\hline 11 & Asperphenalenone $\mathrm{A}$ & 4 & $A(6) D(9) D(8) R(22) R(-)$ & 1.330 \\
\hline 12 & Cytonic acid $\mathrm{A}$ & 4 & $A(3) D(9) D(-) R(19) R(20)$ & 1.290 \\
\hline 13 & Altertoxin I & 4 & $A(1) D(9) D(8) R(-) R(12)$ & 1.244 \\
\hline 14 & Aspergilline $\mathrm{A}$ & 4 & $\mathrm{~A}(6) \mathrm{D}(9) \mathrm{D}(7) \mathrm{R}(-) \mathrm{R}(15)$ & 0.528 \\
\hline 15 & Aspergilline $\mathrm{C}$ & 4 & $\mathrm{~A}(6) \mathrm{D}(9) \mathrm{D}(7) \mathrm{R}(-) \mathrm{R}(17)$ & 0.505 \\
\hline
\end{tabular}


Table 3 Compounds managed to pass Mpro-X77 complex pharmacophore hypothesis using Phase virtual screening

\begin{tabular}{|c|c|c|c|c|}
\hline Entry & Compound name & $\begin{array}{l}\text { Number } \\
\text { of Sites } \\
\text { Matched }\end{array}$ & Matched Ligand Sites & $\begin{array}{c}\text { Phase } \\
\text { Screen } \\
\text { Score }\end{array}$ \\
\hline 1 & Altertoxin V & 4 & $\mathrm{~A}(1) \mathrm{A}(2) \mathrm{R}(12) \mathrm{R}(-) \mathrm{R}(13)$ & 1.522 \\
\hline 2 & Epicocconigrone $\mathrm{A}$ & 4 & $\mathrm{~A}(3) \mathrm{A}(4) \mathrm{R}(17) \mathrm{R}(-) \mathrm{R}(18)$ & 1.428 \\
\hline 3 & Stachybogrisephenone B & 4 & $\mathrm{~A}(4) \mathrm{A}(6) \mathrm{R}(-) \mathrm{R}(14) \mathrm{R}(15)$ & 1.415 \\
\hline 4 & Altertoxin II & 4 & $\mathrm{~A}(2) \mathrm{A}(3) \mathrm{R}(12) \mathrm{R}(-) \mathrm{R}(11)$ & 1.39 \\
\hline 5 & Alternariol 5-O-methyl ether & 4 & $\mathrm{~A}(3) \mathrm{A}(4) \mathrm{R}(11) \mathrm{R}(-) \mathrm{R}(12)$ & 1.373 \\
\hline 6 & Emodin-8-methyl ether & 4 & $\mathrm{~A}(4) \mathrm{A}(1) \mathrm{R}(10) \mathrm{R}(-) \mathrm{R}(11)$ & 1.314 \\
\hline 7 & Emodin & 4 & $\mathrm{~A}(4) \mathrm{A}(3) \mathrm{R}(11) \mathrm{R}(-) \mathrm{R}(10)$ & 1.303 \\
\hline 8 & Altertoxin III & 4 & $\mathrm{~A}(2) \mathrm{A}(6) \mathrm{R}(12) \mathrm{R}(-) \mathrm{R}(13)$ & 1.285 \\
\hline 9 & Altertoxin I & 4 & $\mathrm{~A}(2) \mathrm{A}(4) \mathrm{R}(13) \mathrm{R}(-) \mathrm{R}(12)$ & 1.252 \\
\hline 10 & Griseoxanthone C & 4 & $\mathrm{~A}(3) \mathrm{A}(4) \mathrm{R}(11) \mathrm{R}(12) \mathrm{R}(-)$ & 1.235 \\
\hline 11 & Perlolyrine & 4 & $A(1) A(2) R(7) R(6) R(-)$ & 1.098 \\
\hline 12 & Asperphenalenone A & 4 & $\mathrm{~A}(6) \mathrm{A}(1) \mathrm{R}(23) \mathrm{R}(-) \mathrm{R}(22)$ & 1.094 \\
\hline 13 & Asperphenalenone D & 4 & $\mathrm{~A}(9) \mathrm{A}(5) \mathrm{R}(24) \mathrm{R}(-) \mathrm{R}(23)$ & 1.067 \\
\hline 14 & Altertoxin VI & 4 & $\mathrm{~A}(1) \mathrm{A}(3) \mathrm{R}(11) \mathrm{R}(-) \mathrm{R}(12)$ & 0.973 \\
\hline 15 & Cytonic acids $A$ & 4 & $\mathrm{~A}(5) \mathrm{A}(9) \mathrm{R}(-) \mathrm{R}(21) \mathrm{R}(22)$ & 0.945 \\
\hline 16 & Neosartoryadin B & 4 & $\mathrm{~A}(3) \mathrm{A}(4) \mathrm{R}(-) \mathrm{R}(16) \mathrm{R}(17)$ & 0.939 \\
\hline 17 & Neosartoryadin A & 4 & $A(2) A(5) R(16) R(15) R(-)$ & 0.936 \\
\hline 18 & Cytonic acid B & 4 & $\mathrm{~A}(6) \mathrm{A}(8) \mathrm{R}(22) \mathrm{R}(21) \mathrm{R}(-)$ & 0.876 \\
\hline
\end{tabular}


Table 4 Docking scores and the contributing binding residues of known PLpro inhibitor GRL0617, Mpro inhibitor X77 and selected top antiviral metabolites generated using XP docking

\begin{tabular}{|c|c|c|}
\hline Compounds & $\begin{array}{l}\text { Glide } \\
\text { Score } \\
(\mathrm{Kcal} / \mathrm{mol})\end{array}$ & Contributing Binding Residues \\
\hline \multicolumn{3}{|r|}{ SARS-CoV2-PLpro } \\
\hline GRL-0617 (Control) & -6.441 & $\begin{array}{l}\text { ASP164, GLN269, TYR268, TYR264, PRO247, PRO248, } \\
\text { LEU162, GLY163, ARG166, MET208, TYR273, GLY271, } \\
\text { CYS270, THR301 }\end{array}$ \\
\hline Aspergilline E & -7.77 & $\begin{array}{l}\text { PRO247, TYR268, ASP164, GLY163, GLY271, TYR264, } \\
\text { LEU162, TYR273, GLN269, GLY266, PRO248, ASN267, } \\
\text { THR301, MET208 }\end{array}$ \\
\hline Cytonic acid A & -7.655 & $\begin{array}{l}\text { GLU161, GLU167, LEU162, GLY163, ASP164, GLN269, } \\
\text { CYS270, TYR264, TYR268, GLY266, PRO248, ASN267, } \\
\text { MET208, ARG166, PRO247, GLY271, LYS157 }\end{array}$ \\
\hline Cytonic acid B & -7.292 & $\begin{array}{l}\text { PRO247, PRO248, TYR273, ASN267, TYR264, GLU167, } \\
\text { GLY266, GLY163, GLU161, LEU162, GLN269, ASP164, } \\
\text { TYR268, MET208 }\end{array}$ \\
\hline $\begin{array}{c}\text { 4- } \\
\text { dehydroxyaltersolanol } \\
\text { A }\end{array}$ & -6.859 & $\begin{array}{l}\text { PRO247, PRO248, TYR273, ASP164, GLY163, GLN269, } \\
\text { GLU167, LYS157, LEU162, TYR268, TYR264, THR301 }\end{array}$ \\
\hline \multicolumn{3}{|r|}{ SARS-CoV2-Mpro } \\
\hline X77 (Control) & -8.52141 & $\begin{array}{l}\text { MET49, ASP187, ARG188, PRO52, VAL42, CYS44, } \\
\text { HIS41, THR25, LEU27, THR26, CYS145. ASN142, } \\
\text { GLY143, SER144, HIS163, PHE140, LEU141, GLU166, } \\
\text { HIS172, LEU167, TYR54, HIS164, GLN189, MET165, } \\
\text { PRO168 }\end{array}$ \\
\hline Cytonic acid B & -9.998 & $\begin{array}{l}\text { HIS41, ASP187, GLY170, GLU166, LEU167, ALA191, } \\
\text { GLN192, GLN189, THR190, PRO168, ARG188, MET165, } \\
\text { CYS145, ASN142, MET49, THR25, THR24, SER46, } \\
\text { LEU27, GLY143, HIS164, THR26, TYR54 }\end{array}$ \\
\hline Cytonic acid A & -9.798 & $\begin{array}{l}\text { CYS44, PRO52, MET49, TYR54, HIS41, ASN142, THR26, } \\
\text { THR24, THR25, ASN119, GLY143, TYR118, LEU27, } \\
\text { SER46, THR45, VAL42, GLU166, LEU167, PRO168, } \\
\text { THR190, GLN192, ARG188, GLN189, HIS164, MET165, } \\
\text { ASP187, ASP48 }\end{array}$ \\
\hline Asperphenalenone D & -8.969 & $\begin{array}{l}\text { MET165, VAL186, HIS164, MET49, CYS44, THR45, } \\
\text { SER46, THR25, THR24, GLY143, THR26, LEU27, } \\
\text { CYS145, ASN142, SER144, GLN189, ASP187, PRO168, } \\
\text { ALA191, THR190, LEU167, GLN192, ARG188 }\end{array}$ \\
\hline Asperphenalenone A & -6.2417 & $\begin{array}{l}\text { MET165, CYS44, ARG188, GLN189, MET49, ASN28, } \\
\text { LEU27, VAL42, THR26, ASN119, GLY143, LEU141, } \\
\text { TYR118, ASN142, THR25, THR24, SER46, HIS41, } \\
\text { HIS163, SER144, CYS145, GLU166 }\end{array}$ \\
\hline
\end{tabular}


Table 5 Structural and Chemical properties of screened antiviral compounds.

\begin{tabular}{|c|c|c|c|c|c|c|c|}
\hline $\begin{array}{l}\text { Name of the } \\
\text { Compounds }\end{array}$ & Structure & $\begin{array}{c}\text { Molecular } \\
\text { Weight }\end{array}$ & $\log P$ & $\begin{array}{c}\text { \#Rotatable } \\
\text { Bonds }\end{array}$ & \#Acceptors & \#Donors & $\begin{array}{c}\text { Surface } \\
\text { Area }\end{array}$ \\
\hline GRL0617 & & 304.393 & 4.22142 & 3 & 2 & 2 & 135.68 \\
\hline $\mathrm{X} 77$ & & 459.594 & 4.9392 & 6 & 4 & 2 & 200.565 \\
\hline Cytonic acid A & & 580.63 & 6.2833 & 13 & 9 & 5 & 243.338 \\
\hline
\end{tabular}




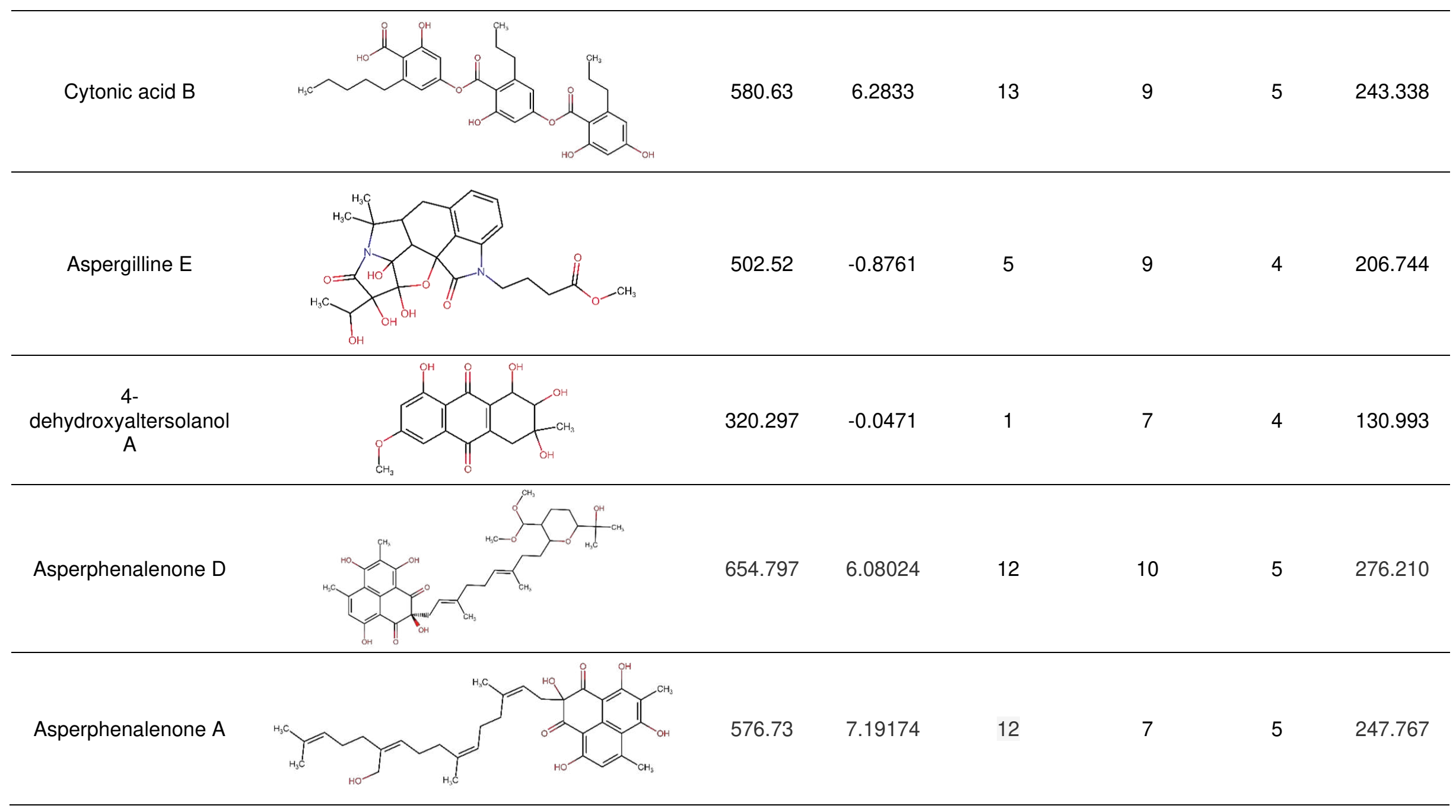


Table 6 MM-GBSA binding free energy change profiles of ligands with SARS-CoV2-PLpro and SARS-CoV2-Mpro for docked complexes.

\begin{tabular}{|c|c|c|c|c|c|c|}
\hline Ligand & $\begin{array}{c}\Delta \text { GBind } \\
\text { (Kcal/mol) }\end{array}$ & $\begin{array}{c}\Delta \text { GCoulomb } \\
\text { (Kcal/mol) }\end{array}$ & $\begin{array}{l}\Delta \text { GHbond } \\
\text { (Kcal/mol) }\end{array}$ & $\begin{array}{c}\Delta \text { GLipo } \\
\text { (Kcal/mol) }\end{array}$ & $\begin{array}{c}\Delta \text { GPacking } \\
\text { (Kcal/mol) }\end{array}$ & $\begin{array}{c}\Delta G v d W \\
(\mathrm{Kcal} / \mathrm{mol})\end{array}$ \\
\hline \multicolumn{7}{|c|}{ Ligands interacting with SARS-CoV2-PLpro } \\
\hline GRL-0617 (Control) & -67.5637 & -20.1695 & -2.5442 & -26.1400 & -3.1440 & -46.3768 \\
\hline Aspergilline E & -50.8186 & -17.1949 & -1.24148 & -18.2587 & -0.54685 & -35.848 \\
\hline Cytonic acid A & -58.9626 & -34.7886 & -2.45573 & -20.7273 & -2.897 & -42.5047 \\
\hline Cytonic acid B & -55.6721 & -28.8001 & -1.74414 & -25.71 & -3.10166 & -52.1166 \\
\hline 4-dehydroxyaltersolanol A & -38.3654 & -22.0615 & -3.34432 & -14.1614 & -1.84419 & -31.2361 \\
\hline \multicolumn{7}{|c|}{ Ligands interacting with SARS-CoV2-Mpro } \\
\hline X77 (Control) & -79.8911 & -35.3714 & -1.8857 & -17.6157 & -3.0805 & -59.5617 \\
\hline Cytonic acid A & -75.3087 & -36.7368 & -4.0966 & -16.7277 & -0.5834 & -58.2717 \\
\hline Cytonic acid B & -67.6847 & -41.9421 & -3.7410 & -13.1996 & -1.6820 & -54.3987 \\
\hline Asperphenalenone D & -65.9103 & -24.9700 & -2.4700 & -16.5780 & -1.7280 & -50.2750 \\
\hline Asperphenalenone A & -50.4602 & -10.6094 & -1.8999 & -11.8471 & -2.2800 & -52.6731 \\
\hline
\end{tabular}

Note, meaning of abbreviations used in the table are as follows:

Coulomb-Coulomb energy

Hbond-Hydrogen-bonding correction

Lipo-Lipophilic energy

Packing-Pi-pi packing correction

vdW-Van der Waals energy 
Table 7 ADMET properties of screened antiviral compounds.

\begin{tabular}{|c|c|c|c|c|c|c|c|c|c|c|}
\hline \multirow[b]{2}{*}{ Property } & \multirow[b]{2}{*}{ Model Name } & \multicolumn{8}{|c|}{ Predicted values } & \multirow[b]{2}{*}{ Unit } \\
\hline & & GRL0617 & $X 77$ & $\begin{array}{l}\text { Cytonic } \\
\text { acid A }\end{array}$ & $\begin{array}{l}\text { Cytonic } \\
\text { acid B }\end{array}$ & $\begin{array}{c}\text { Aspergilline } \\
\text { E }\end{array}$ & $\begin{array}{c}4 \\
\text { dehydroxyal } \\
\text { tersolanol A }\end{array}$ & $\begin{array}{l}\text { Asperphen } \\
\text { alenone D }\end{array}$ & $\begin{array}{l}\text { Asperphen } \\
\text { alenone A }\end{array}$ & \\
\hline Absorption & $\begin{array}{c}\text { Water } \\
\text { solubility }\end{array}$ & -4.678 & -2.878 & -2.902 & -2.914 & -2.639 & -2.009 & -3.495 & -3.746 & $\begin{array}{c}\text { Numeric } \\
(\log \mathrm{mol} / \mathrm{L})\end{array}$ \\
\hline Absorption & $\begin{array}{c}\mathrm{CaCO} 2 \\
\text { permeability }\end{array}$ & 1.302 & 1.29 & -1.108 & -1.17 & 0.697 & 0.633 & -0.093 & -0.172 & $\begin{array}{c}\text { Numeric } \\
\text { (log Papp in } \\
10^{-6} \mathrm{~cm} / \mathrm{s} \text { ) }\end{array}$ \\
\hline Absorption & $\begin{array}{l}\text { Intestinal } \\
\text { absorption } \\
\text { (human) }\end{array}$ & 92.815 & 89.686 & 46.99 & 62.692 & 56.317 & 67.204 & 76.573 & 79.961 & $\begin{array}{c}\text { Numeric (\% } \\
\text { Absorbed) }\end{array}$ \\
\hline Absorption & $\begin{array}{c}\text { Skin } \\
\text { Permeability }\end{array}$ & -2.785 & -2.735 & -2.735 & -2.735 & -2.735 & -2.848 & -2.735 & -2.735 & $\begin{array}{c}\text { Numeric } \\
(\log \mathrm{Kp})\end{array}$ \\
\hline Absorption & $\begin{array}{l}\text { P-glycoprotein } \\
\text { substrate }\end{array}$ & Yes & Yes & Yes & Yes & Yes & Yes & Yes & Yes & $\begin{array}{c}\text { Categorical } \\
\text { (Yes/No) }\end{array}$ \\
\hline Absorption & $\begin{array}{l}\text { P-glycoprotein } \\
\text { I inhibitor }\end{array}$ & No & Yes & No & No & Yes & No & Yes & Yes & $\begin{array}{c}\text { Categorical } \\
\text { (Yes/No) }\end{array}$ \\
\hline Absorption & $\begin{array}{l}\text { P-glycoprotein } \\
\text { II inhibitor }\end{array}$ & Yes & Yes & No & No & No & No & Yes & Yes & $\begin{array}{c}\text { Categorical } \\
\text { (Yes/No) }\end{array}$ \\
\hline Distribution & VDss (human) & 0.086 & 0.656 & -1.267 & -1.707 & 0.431 & -0.006 & 0.454 & -0.357 & $\begin{array}{c}\text { Numeric } \\
(\log L / k g)\end{array}$ \\
\hline Distribution & $\begin{array}{l}\text { Fraction } \\
\text { unbound } \\
\text { (human) }\end{array}$ & 0 & 0.262 & 0.08 & 0.006 & 0.373 & 0.413 & 0.056 & 0.013 & $\begin{array}{l}\text { Numeric } \\
(\mathrm{Fu})\end{array}$ \\
\hline Distribution & $\begin{array}{c}\mathrm{BBB} \\
\text { permeability }\end{array}$ & 0.055 & -0.899 & -1.896 & -1.782 & -0.969 & -0.844 & -1.67 & -1.404 & $\begin{array}{l}\text { Numeric } \\
(\log B B)\end{array}$ \\
\hline Distribution & $\begin{array}{c}\text { CNS } \\
\text { permeability }\end{array}$ & -1.604 & -2.31 & -3.143 & -3.183 & -3.826 & -3.494 & -3.054 & -2.722 & $\begin{array}{l}\text { Numeric } \\
(\log P S)\end{array}$ \\
\hline Metabolism & $\begin{array}{l}\text { CYP2D6 } \\
\text { substrate }\end{array}$ & No & No & No & No & No & No & No & No & $\begin{array}{c}\text { Categorical } \\
\text { (Yes/No) }\end{array}$ \\
\hline Metabolism & $\begin{array}{l}\text { CYP3A4 } \\
\text { substrate }\end{array}$ & Yes & No & No & No & No & No & Yes & Yes & $\begin{array}{c}\text { Categorical } \\
\text { (Yes/No) }\end{array}$ \\
\hline Metabolism & $\begin{array}{l}\text { CYP1A2 } \\
\text { inhibitor }\end{array}$ & Yes & No & No & No & No & No & No & No & $\begin{array}{c}\text { Categorical } \\
\text { (Yes/No) }\end{array}$ \\
\hline
\end{tabular}




\begin{tabular}{|c|c|c|c|c|c|c|c|c|c|c|}
\hline Metabolism & $\begin{array}{l}\text { CYP2C19 } \\
\text { inhibitor }\end{array}$ & Yes & No & No & No & No & No & No & No & $\begin{array}{c}\text { Categorical } \\
\text { (Yes/No) }\end{array}$ \\
\hline Metabolism & $\begin{array}{l}\text { CYP2C9 } \\
\text { inhibitor }\end{array}$ & Yes & No & No & No & No & No & No & No & $\begin{array}{c}\text { Categorical } \\
\text { (Yes/No) }\end{array}$ \\
\hline Metabolism & $\begin{array}{l}\text { CYP2D6 } \\
\text { inhibitor }\end{array}$ & No & No & No & No & No & No & No & No & $\begin{array}{c}\text { Categorical } \\
\text { (Yes/No) }\end{array}$ \\
\hline Metabolism & $\begin{array}{l}\text { CYP3A4 } \\
\text { inhibitor }\end{array}$ & Yes & Yes & No & No & No & No & Yes & Yes & $\begin{array}{c}\text { Categorical } \\
\text { (Yes/No) }\end{array}$ \\
\hline Excretion & $\begin{array}{c}\text { Total } \\
\text { Clearance }\end{array}$ & 0.221 & 0.671 & 0.268 & 0.183 & 0.143 & 0.453 & -0.035 & 0.071 & $\begin{array}{c}\text { Numeric } \\
(\log \\
\mathrm{ml} / \mathrm{min} / \mathrm{kg})\end{array}$ \\
\hline Excretion & $\begin{array}{c}\text { Renal OCT2 } \\
\text { substrate }\end{array}$ & No & Yes & No & No & No & No & No & No & $\begin{array}{c}\text { Categorical } \\
\text { (Yes/No) }\end{array}$ \\
\hline Toxicity & AMES toxicity & Yes & Yes & No & No & No & No & No & No & $\begin{array}{c}\text { Categorical } \\
\text { (Yes/No) }\end{array}$ \\
\hline Toxicity & $\begin{array}{l}\text { Max. tolerated } \\
\text { dose (human) }\end{array}$ & -0.043 & 0.601 & 0.44 & 0.467 & -0.645 & -0.078 & 0.229 & 0.191 & $\begin{array}{c}\text { Numeric } \\
(\log \\
\mathrm{mg} / \mathrm{kg} / \text { day })\end{array}$ \\
\hline Toxicity & $\begin{array}{l}\text { hERG I } \\
\text { inhibitor }\end{array}$ & No & No & No & No & No & No & No & No & $\begin{array}{c}\text { Categorical } \\
\text { (Yes/No) }\end{array}$ \\
\hline Toxicity & $\begin{array}{l}\text { hERG II } \\
\text { inhibitor }\end{array}$ & Yes & Yes & No & No & No & No & Yes & Yes & $\begin{array}{c}\text { Categorical } \\
\text { (Yes/No) }\end{array}$ \\
\hline Toxicity & $\begin{array}{c}\text { Oral Rat Acute } \\
\text { Toxicity } \\
\text { (LD50) }\end{array}$ & 2.472 & 2.396 & 2.499 & 2.444 & 2.302 & 1.923 & 2.253 & 2.042 & $\begin{array}{l}\text { Numeric } \\
(\mathrm{mol} / \mathrm{kg})\end{array}$ \\
\hline Toxicity & $\begin{array}{c}\text { Oral Rat } \\
\text { Chronic } \\
\text { Toxicity } \\
\text { (LOAEL) }\end{array}$ & 0.462 & 1.528 & 2.897 & 2.891 & 3.695 & 2.734 & 1.602 & 2.462 & $\begin{array}{c}\text { Numeric } \\
\text { (log } \\
\mathrm{mg} / \mathrm{kg} \text { _bw/ } \\
\text { day) }\end{array}$ \\
\hline Toxicity & Hepatotoxicity & No & Yes & No & No & No & No & No & No & $\begin{array}{c}\text { Categorical } \\
\text { (Yes/No) }\end{array}$ \\
\hline Toxicity & $\begin{array}{c}\text { Skin } \\
\text { Sensitisation }\end{array}$ & No & No & No & No & No & No & No & No & $\begin{array}{c}\text { Categorical } \\
\text { (Yes/No) }\end{array}$ \\
\hline Toxicity & $\begin{array}{l}\text { T. pyriformis } \\
\text { toxicity }\end{array}$ & 0.529 & 0.285 & 0.285 & 0.285 & 0.285 & 0.287 & 0.285 & 0.286 & $\begin{array}{l}\text { Numeric } \\
\text { (log ug/L) }\end{array}$ \\
\hline Toxicity & $\begin{array}{l}\text { Minnow } \\
\text { toxicity }\end{array}$ & 1.936 & 2.563 & 1.089 & 0.011 & 4.392 & 4.044 & -2.806 & -4.272 & $\begin{array}{l}\text { Numeric } \\
(\log \mathrm{mM})\end{array}$ \\
\hline
\end{tabular}

